\title{
Advances in the treatment of explicit water molecules in docking and binding free energy calculations
}

\author{
Xiao $\mathrm{Hu},{ }^{\mathrm{a}}$ Irene Maffucci, ${ }^{\mathrm{b}}$ and Alessandro Contini $\mathrm{a}^{\mathrm{*}}$ \\ a Università degli Studi di Milano, Dipartimento di Scienze Farmaceutiche, Sezione \\ di Chimica Generale e Organica “A. Marchesini”, Via Venezian, 2120133 Milano, \\ Italy \\ b Pasteur, Département de Chimie, École Normale Supérieure, PSL Research \\ University, Sorbonne Universités, UPMC Univ. Paris 06, CNRS, 75005 Paris, France \\ * corresponding author: e-mail alessandro.contini@unimi.it; tel. +39.02.50314480
}

\begin{abstract}
Background: The inclusion of direct effects mediated by water during the ligandreceptor recognition is a hot-topic of modern computational chemistry applied to drug discovery and development. Docking or virtual screening with explicit hydration is still debatable, despite the successful cases that have been presented in the last years. Indeed, how to select the water molecules that will be included in the docking process or how the included waters should be treated remain open questions.
\end{abstract}

Objective: In this review, we will discuss some of the most recent methods that can be used in computational drug discovery and drug development when the effect of a single water, or of a small network of interacting waters, needs to be explicitly considered.

Results: Here, we analyse software to aid the selection, or to predict the position, of water molecules that are going to be explicitly considered in later docking studies. We also present software and protocols able to efficiently treat flexible water molecules during docking, including examples of applications. Finally, we discuss methods based on molecular dynamics simulations that can be used to integrate docking studies or to reliably and efficiently compute binding energies of ligands in presence of interfacial or bridging water molecules.

Conclusions: Software applications aiding the design of new drugs that exploit water molecules, either as displaceable residues or as bridges to the receptor, are constantly being developed. Although further validation is needed, workflows that explicitly consider water will probably become a standard for computational drug discovery soon.

\section{Introduction}

Since the beginning of modern medicinal chemistry, scientists have relied on models to explain or to improve the activity of drugs. Nowadays, methodology advances in computational chemistry have made molecular models much more accurate, even if they still include many simplifications and approximations. Nevertheless, molecular 
This is a post print version of the article published in Curr Med Chem. 2018 May 13. doi:

$10.2174 / 0929867325666180514110824$

http://www.eurekaselect.com/162094/article

modelling is now an obliged passage of drug discovery and development process.[15] The needs for higher accuracy, as well as the constantly increasing computational power, drives developers to create more sophisticated models.

The inclusion of direct effects mediated by water during the ligand-receptor recognition is one of the topics that are currently drawing much of the attention. The analysis of a few thousands of crystallographic protein-ligand complexes showed that one or more water molecules are involved in ligand binding,[6,7] Moreover, Lu and co-workers found that more than $50 \%$ of the water molecules observed in 392 highresolution complexes actually were bridging waters.[8]

The potential role of water in the drug design process has been long recognized. Medicinal chemists often dealt with the possibility to displace a water molecule from the binding site benefitting from the entropy change during the binding process, or to use it as a bridge anchoring the ligand to the receptor.[9] However, making a smart choice between the two strategies is only possible if the binding thermodynamics of the considered water can be reasonably predicted, since no simple experimental methods exist to evaluate the energetics of individual water molecules.

The importance of considering water in computational drug design has already been reviewed and some of the applications that can be used for this purpose have also been discussed.[10-12] However, considering the constant improvements in software design and the awareness of usefulness in applications over years, in this article we intend to provide to medicinal chemists a synoptic discussion of the available computational methods. These include principally those developed in the last decade, which are capable of taking water into account in drug design.

To include explicit water molecules into docking or virtual screening studies, some crucial questions need to be considered: how the water molecules are positioned? Which ones are the most important to be included for later study? How explicit hydration is treated by the docking software of preference? Should the water molecules be fully flexible during docking? How water displaceability and free energy or score contribution is considered?

In the following sections, we will try to address these questions alongside with potential solutions, and provide current options related to docking or virtual screening with explicit hydration.

Indeed, we will analyse some software that can aid the selection of important water, whose coordinates are obtained by experiments or by calculations, for later docking studies. Then, we will discuss how flexible water molecules can be efficiently treated during docking. Finally, we will report on some of the recent methods based on molecular dynamics (MD) simulations that can be used to tackle specific question related to the role played by water molecules in the ligand-receptor recognition process.

\section{Hydration Sites Selections or Predictions}

\subsection{Water selection methods based on experimental data}


This is a post print version of the article published in Curr Med Chem. 2018 May 13. doi: $10.2174 / 0929867325666180514110824$

http://www.eurekaselect.com/162094/article

One of the prevalent and acknowledged water positioning methods is the use of highresolution X-ray crystallographic structures. This method is generally trustworthy and able to provide precious information on tightly bound water molecules at the binding site. $[13,14]$ Nevertheless, it is important to be aware that X-ray structures, though being the most resolved representation of molecular geometry we can currently generate by experiments, provide rather "static" information, collected at a relatively low temperature and with a well-ordered structural arrangement. Moreover, interpreting the electron density to obtain the averaged position of the atoms provides that the outcome for some water molecules remains dubious, especially at a relatively poor resolution. Additionally, the method inevitably suffers from all the intricate requirements that detain its application to a wider range of biomolecular systems. Nonetheless, well-acknowledged successes related to the HIV-1 protease were accomplished using the information of conserved water molecules experimentally determined at the binding site.[15-20] Thus, it is reasonable to consider that the same logic might apply to other systems. Multiple methods have been developed using this philosophy to estimate conserved water positions using information available in public databases (e.g. Protein Data Bank,[21] PDB, Cambridge Structural Database,[22] CSD). In addition, multiple auxiliary databases have been developed to address the importance of ligand-protein interactions (e.g. Binding MOAD[23,24], PDBbind[25,26], and BindingDB[27,28]).

One of the experiments-based methods, Consolv,[29] analyses the environment of explicit water molecules at the active site to estimate their conservativity using single or multiple crystal structure(s). The crystallographic B-factor is considered as one of the environmental evaluation criteria, aside from the number of closest protein atoms around the water molecules (i.e. atomic density), the hydrophilicity of the hydration site, and the number of water-protein hydrogen bonds. Moreover, Consolv also allows conservation tests among multiple crystal structures using the k-nearest-neighbour genetic algorithm. The method was validated on 7 testing complexes, reaching a $75 \%$ prediction accuracy. However, $83 \%$ of false positive positions were replaced by polar atoms from the ligands in the original complexes, implying a potential $90 \%$ accuracy.

The evaluation of the interactions made by different water molecules found in a protein binding site can also be tackled as a typical protein-ligand scoring problem.[30] Several scoring methods were indeed developed to describe protein ligand interactions, [31] the most common being empirical (or regression-based) [3234] and force field-based (or physics-based) scoring functions,[35-37] and the same theory can thus be applied to water.

WaterScore was indeed developed as a scoring method to estimate conserved water molecules using a logistic regression analysis and multiple structural properties, derived from crystal structures.[38] Three structural properties are considered in the scoring function: the temperature B-factor, the solvent contact surface area, and the number of protein atomic contacts. The method provided a moderate prediction efficiency ranging from 67.4 to $71.7 \%$. The author later published a complete statistic study on energetic and physicochemical properties of tightly bound water molecules. The analysis was carried out on 2332 high-resolution crystal structures, but results were inconclusive,[39] probably due to the modest prediction ability of the method. In 
This is a post print version of the article published in Curr Med Chem. 2018 May 13. doi:

$10.2174 / 0929867325666180514110824$

http://www.eurekaselect.com/162094/article

another work, WaterScore, followed by thermodynamic integration free energy calculations, was successful in determining a tightly bound water molecule in the enzyme Abl-SH3 domain tyrosine kinase in complex with a peptide.[40]

Force-field-like scoring methods were also developed to characterise explicit water in biomolecules. For instance, HINT[41] uses a non-Newtonian force field based on experimentally determined $\log \mathrm{P}$ between octanol and water $\left(\log \mathrm{P}_{\mathrm{o} / \mathrm{w}}\right)$ and a Rank algorithm[42] for water scoring and optimisation. The method was tested on 4 apo proteins with 50 active site water molecules. The outcome was then compared to those observed in the holo complexes; $76 \%$ water positions were accurately predicted.[41] A later study, performed on 9 apo/holo structures, predicted $87 \%$ of the 68 conserved water molecules.[43] Multiple follow-up works were carried out, covering protein-protein interactions, [44-46] protein-ligand interactions, [47] and the design of inhibitors targeting O-acetylserine sulfhydrylase,[48] thrombin,[49] cystalysin,[50] and human serine racemase.[51]

Though potentially accurate, these methods require extensive amount of inputs and $a$ priori knowledge, including extended experimental data. Indeed, one or multiple well-resolved crystal structure(s) should be acquired, generally with a large amount of trials and errors. These requirements probably hindered the applications of some methods in early drug design studies, especially on those biomolecular systems which are difficult to crystallise. Thus, efficient prediction tools which are not very strict on input data, but still provide an acceptable accuracy, are deemed necessary for drug design.

\subsection{In silico methods predicting water positions}

Two pathways can be followed to virtually place water at the active sites: the water molecules can be positioned either before or after docking experiments. The former approach is more closely recreating the real solvated binding scenario. The successful docking greatly depends on the ability of the ligand to displace water molecules, or the adaptability to the favourable poses due to effective bridging interactions. On the other hand, water placement after docking is more effective in filling up the space between ligand and receptor, potentially improving the binding free energy by altering the chemical properties about the protein surface. However, this is at the cost of losing some ligand adaptability due to the pre-determined "dry" poses. This could be particularly true if the docked complexes are hold static. Moreover, these "dry" poses could also be incorrect, as demonstrated by Roberts and Mancera, who improved their pose predictions by including explicit water molecules during docking.[52] Nonetheless, the usefulness of these methods should not necessary be excluded, as they might still be worthwhile, for example when an accurate pose predictions has already been achieved, but improved free energy estimations are expected.

Pre-docking prediction of solvation sites. Based on the reference interaction site model (RISM) theory[53-56], the three-dimensional RISM with the closure relation by Kovalenko and Hirata (3D-RISM-KH) theory[57-59] has become more widely applied to analyse the solute-solvent interface for water configurations. The RISM theory essentially applies the first principles foundations of statistical mechanics and reduced Ornstein-Zernike integral equation theory[60] to the liquid state of matter. 
This is a post print version of the article published in Curr Med Chem. 2018 May 13. doi: $10.2174 / 0929867325666180514110824$

http://www.eurekaselect.com/162094/article

The generalisation of the solute-solvent RISM equations,[57] in combination with the closure relation suggested by Kovalenko and Hirata,[58] enables the 3D mapping of solvent distributions around an arbitrarily shaped solute molecule. The detailed theoretical background has been well expounded and reviewed in a variety of reading materials.[58,61-64] In recent years, successful applications of the 3D-RISM-KH theory within multiple solvated biomolecular systems has also been reported.[65-70] This prevalence in applications is likely related to the solid theoretical platform it stands on and the more efficient computational algorithm involving solving solely the integral equations, revealing a comprehensive solvation structure in the statisticalmechanical ensembles. This provides a feasible and powerful alternative for studies related to very complex systems that cannot be easily handled by molecular simulations.

Using the 3D-RISM-KH integral equation theory, multiple thermodynamic properties can be calculated, one of which is the 3D distribution function. Placevent, developed by Sindhikara and co-workers, utilises this property to derive discrete solvent positions around the solute of interest.[71] The method was validated on both KNI272-bound HIV-1 protease and F-type $\mathrm{Na}^{+}$-ATPase. All six of the important water molecules of HIV-1 protease were found from a blank test and also those of the ATPase.[71] The 3D-RISM-KH theory combined with Placevent became a standard hydration analysis in a variety of studies. Recent applications include facilitating protein NMR shift calculations in explicit solvent,[72,73] solvation of channelrhodopsin cation channels, [74] predicting bound water molecules for BCRABL kinase inhibitor design,[75] and providing initial solvated model for MD simulations of ATP-bound Akt1 complex.[76] Stumpe et al. also demonstrated that the water densities generated by 3D-RISM-KH remarkably agreed with that from MD simulations.[77] This exhibits the powerfulness of 3D-RISM-KH even when static conformations are used. However, it was noted that the method is not yet suitable for solvation free energy calculation due to intrinsic drawbacks brought about by the closure approximations and the applied force field. Thus, though with good accuracy in depicting water positions, the method is not recommended to be incorporated into free energy calculations.

The continuously increasing power of modern hardware, allows protocols based on MD or Monte Carlo (MC) simulations to become an alternative to predict the position of potential important water molecules within binding site. The inhomogeneous solvation theory (IST or IFST)[78-80] provides the theoretical background to build up solvation energy profiles of systems using molecular simulations. One method adapting this theory, WaterMap, uses MD simulations for prior-docking water mapping[81,82] and has become well practiced within the Schrödinger SmallMolecule Drug Discovery Suite.[83] The mapping procedure starts with a MD simulation of the restrained protein or complex in explicit solvent. The location and the orientation of every water molecule within the binding site are recorded into a density profile during the simulation. The water molecules are then mapped at gridded positions with a density higher than that of the bulk solvent. Enthalpy and entropy energy terms are then evaluated using a modified IST. Moreover, the Glide XP scoring function was modified, namely WScore, to incorporate more accurate solvent 
This is a post print version of the article published in Curr Med Chem. 2018 May 13. doi:

$10.2174 / 0929867325666180514110824$

http://www.eurekaselect.com/162094/article

interactions and some receptor flexibility in docking using WaterMap procedures. $[84,85]$ The overall protocol and applications will be thoroughly reviewed in later section.

The applications of WaterMap took off since its early release, mainly in investigating structure-activity relationship,[86-88] designing potentially active molecules,[89-91] and exploring druggable sites.[92] Some examples include adenosine $A_{2 A}[87,93]$ and other G protein coupled receptors,[94] human carbonic anhydrase (HCA),[95] lactate dehydrogenase A (LDH-A),[96] dopamine D3 receptor,[97] serine proteases,[98] farnesyl pyrophosphate synthase,[99] penicillin-binding protein 3,[100] Janus kinases (JAKs),[90] and proprotein convertase subtilisin-kexin type 9.[101] Most of these studies involve evaluations of solvent thermodynamic properties at the binding site, implying a relatively robust and mature application in the field. Relative binding free energies were also computed with WaterMap, but only within congeneric series of ligands for which the desolvation of the binding site, rather than specific ligand interactions, was the main driver of the binding thermodynamics (e.g. within highly hydrophobic pockets).[81,102]

One intrinsic drawback of applying MD simulation is related to proper equilibration of buried water molecules.[103-106] The relatively short simulation generally used in WaterMap calculations might fail to sample positions about more buried region at the binding site. This is likely severe for ligand-bound complexes. Wang and co-workers have applied a grand canonical Monte Carlo (GCMC) step prior to MD simulation to overcome this demerit.[107] Likewise, other viable methods can also be applied if deemed necessary. Another disadvantage of WaterMap is that the simulated system is not allowed for relevant conformational changes during the solvation process, since protein restraints are applied during MD.[11] Hence, some receptor relaxation in solvent might be lost. Moreover, although able to correctly predict the position of water molecules in a network, it cannot calculate the binding free energy of networked waters.

The grid inhomogeneous solvation theory (GIST) was also proposed.[108-110] GIST allows the calculations of water occupancy, and enthalpic and entropic energetics on a 3D grid, instead of at discrete hydration sites. GIST is implemented in the AmberTools cpptraj package[110,111] and was recently combined with AutoDock4[112] to incorporate water thermodynamics in virtual screening.[113] The authors demonstrated improvements in docking pose predictions and in virtual screenings for the coagulation factor Xa. A non-commercial alternative to WaterMap is the Solvation Thermodynamics of Ordered Water (STOW) package.[114] Similarly to WaterMap, the method uses a water trajectory from MD simulations and applies the IST to determine the thermodynamic properties of isolated or clustered water molecules. STOW has been successfully used in studies on several biological systems including HIV1-protease, Concanavalin A in complex with carbohydrates, and cyclophilin A.[115-118]

Other than applying IST related methods, information on hydration sites can also be derived from averaged Gaussian distribution functions. WATsite takes up this strategy to identify important water molecules from a MD simulation implemented within a 
This is a post print version of the article published in Curr Med Chem. 2018 May 13. doi:

$10.2174 / 0929867325666180514110824$

http://www.eurekaselect.com/162094/article

Pymol plugin.[119] The method reads information from a MD trajectory of the protein in the apo or in the holo state. The protein binding site needs to be defined before running the simulation, and a ligand or a pseudo-ligand must be positioned in the binding pocket. A margin value is also required to define the final box size to enclose the binding site. Successively, for each MD frame, the positions of the oxygen atoms of waters within the binding site are recorded. Gaussian distribution functions are established about each oxygen centre on a 3D grid and averaged over the whole MD simulation. A quality threshold clustering algorithm is then applied to determine locations with peaked water occupancies as the hydration sites. The desolvation free energy is then calculated from solvent entropic and enthalpic surpluses to the bulk solvent for each hydration site. Analogous to WaterMap and related methods, a positive desolvation free energy indicates unstable water molecules; replacement of these water molecules by ligands should improve the final binding free energy.[120] This program is able to run all the steps necessary to the definition and visualization of hydration sites, starting from the structure preparation. Moreover, if combined with a pharmacophore modelling tool, WATsite can be employed to derive protein-based pharmacophore model. The use of such "water aware" pharmacophores led to higher computational efficiency maintaining the enrichment performance, compared to other models where hydration sites were not considered.[120]

However, WATsite is only compatible for Gromacs MD trajectory for the hydration site analysis. Alternatively, a similar tool, WATCLUST,[121] was developed as a $V M D[122]$ plugin to allow analyses on previously loaded MD trajectories. WATCLUST can be called from the Extensions $\rightarrow$ Analysis menu to compute hydration sites around specific residues, together with water site-protein interaction energy and other thermodynamic parameters. Additionally, the obtained water sites can be used to generate water biased grid maps for subsequent docking studies with AutoDock.

As an alternative to MD-based methods, MC simulations might be beneficial for those systems whose binding sites are either occupied by a ligand or hardly accessible to solvent. Just Add Water Molecules (JAWS or JAWM),[123] currently implemented in a modified version of $M C P R O$ (v. 2.1),[124] is a rather recent MC method that can operate on both apo or holo proteins. The method requires a 3D grid formed by overlapping spheres centred on each atom of the ligand or of a user-selected group of atoms of the protein. Initially, putative hydration sites are guessed by randomly positioning water molecules on the grid. A MC step is then performed to generate a probability distribution of the water occupancies. An additional degree of freedom, $\theta$, representing the "water-likeness" of each hydration site, is introduced in the MC step.[123] The fractional water occupancies obtained in the previous step are then clustered into a defined number of possible hydration sites. In a second step, a biasing potential is applied to each water molecule identified previously, and a new MC simulation is performed for each water to establish the amount of time the molecule is interacting with the system. This procedure allows the estimation of the binding free energy for each water molecule. JAWS was initially validated on five biomolecular systems. The method performed well in predicting well-buried water molecules, but it required protocol adjustments for solvent exposed pockets. A consensus analysis of 
This is a post print version of the article published in Curr Med Chem. 2018 May 13. doi:

$10.2174 / 0929867325666180514110824$

http://www.eurekaselect.com/162094/article

multiple setups was also recommended. Cautions should be taken as JAWS is also ligand-dependent, but the method also works with apo proteins. The method was further validated on three protein-ligand complexes,[125] and more intensively, on inhibitor binding for p38r MAP kinase,[126] followed by MC free energy perturbation calculations. JAWS has also been applied before an enhanced MC method to confirm the unfavourable placement of water in a cavity.[127]

Grand canonical Monte Carlo (GCMC) technique, another branch of MC methods, was initially introduced in 1974[128] and adapted to hydration analysis in 19902000s.[129-132] GCMC allows number of particles in the system to fluctuate during the simulation. This is accomplished by coupling the system to an ideal gas reservoir at a constant chemical potential. Recently, Ross and co-workers developed the method further to overcome its previous limitations.[133] The grand canonical integration (GCI) was incorporated to allow optimisation of the number of solvent molecules though minimising the Helmholtz free energy state. The calculated hydration free energy in bulk solvent was in excellent agreement with experimental data. Additionally, in small cavities at protein-ligand interfaces, GCI calculation of free energy was satisfactorily close to that from replica exchange thermodynamic integration. With this implementation, GCMC can be applied to compute the binding free energies of entire water networks through water titration plots.[134,135] Moreover, this approach can also be used as a water placement tool. It was noted that it is important to achieve full convergence of the number of water molecules for reliable predictions.

$J A W S$, GCMC and double-decoupling (a rigorous alchemical method based on MD and statistical thermodynamics [136]) were compared side-by-side in a later study on zanamivir in complex with N9-neuraminidase.[137] The three methods yielded consistent results in the calculation of water binding free energy, though JAWS and GCMC resulted 10 times faster than double-decoupling. However, this higher efficiency was still in the range of 30 hours using $162.6 \mathrm{GHz}$ processors.[137] Moreover, issues with JAWS can arise if extensive overlaps of population densities occur, possibly leading to difficulties in clustering into separate hydration sites.

Water molecules can also be positioned through docking. WaterDock adopted this idea by using AutoDock Vina[138] to dock a single water molecule into the binding sites within a cubic space of $15 \AA$ edge length.[139] Both locations and poses of the water molecule were recorded from repeated docking processes. The author reported 97\% accurate predictions among 14 structures of OppA-lysine-X-lysine-tripeptide complexes, and $88 \%$ within another set of X-ray structures.[139] The prediction of displaceable water by WaterDock was validated using the Astex Diverse Set[140] with an accuracy of 75\%.[139] A promising perspective regarding this method is the highly efficient calculation due to the application of AutoDock Vina; the prediction can be done within seconds. A study on CDK9 applied WaterDock for binding site hydration.[141] The applications among the other studies are mainly in the validation domain for conserved water molecules in crystal structures.[142-144]

WaterDock has been incorporated into another solvation program, Dowser++, to accurately predict water at protein interiors.[145] The latter is a development of the 
This is a post print version of the article published in Curr Med Chem. 2018 May 13. doi:

$10.2174 / 0929867325666180514110824$

http://www.eurekaselect.com/162094/article

Dowser software,[146] performing the calculation on the whole protein space followed by further analysis. This tandem analyses provided a false-positive rate much lower than using WaterDock alone.[145] The authors suggested that the high false positive rate was likely intrinsically determined by the local performance of AutoDock Vina at the binding site; the Vina methodology is probably not suitable for whole-protein docking.[145] The authors of WaterDock also addressed the potential drawback of the program regarding the false-positive rate, recorded at $24 \%$ for one test set.[147] Thus, a new version, WaterDock 2.0, was introduced with improvements from this standpoint.[147] The solvation behaviour of small molecules was included as an additional criterion based on the hydrogen bond saturation limit. Information on the hydration shell was derived from preliminary MD simulations. It was shown that the method provided a 50\% improvement in false positive occurrence within ligandprotein complexes.

The importance of water molecules at binding sites can also be assessed from their desolvation due to their proximity to the solute. OpenEye's SZMAP [148] resembles the well-known GRID method[149] to some extent. It provides the option of combining explicit water molecule with a Poisson-Boltzmann solvent continuum[150] (i.e. a semi-continuum solvation) and classical statistical mechanics. The method calculates thermodynamic quantities at gridded points using a water probe at multiple orientations, interacting simultaneously with the high dielectric continuum and the solute(s). The polar and apolar sites are distinguished using the free energy difference from charged to uncharged $\left(\mathrm{CH}_{2}\right.$-like) water molecule, using $\mathrm{PB}$ calculations with adjusted partial charges on the hydrogens and oxygen. The performance of SZMAP was assessed on a variety of crystal complexes.[151] Decent results were obtained in predicting conserved waters and in correlation to experimental B-factor.

Another prediction tool, SuperStar,[152-154] empirically applies non-bonded information collected from experimental data, i.e. the IsoStar scatterplots based on the CSD and PDB.[154,155] Though designed for predicting protein-ligand interactions, it also provides a high success rate $(88 \%)$ in mapping explicit hydration in proteinligand complexes.[153] Multiple applications in mapping functional group interactions were reported so far.[156-160] In one example, SuperStar calculations integrated 3D-QSAR results providing a rationale for high affinity ligands interacting with hydrophobic residues through a polar group.[161] It was indeed observed that the relatively apolar side-chains were able to accommodate a water molecule acting as a hydrogen bond acceptor.

Post-docking prediction of solvation sites. Though post-docking positioning of water molecules could potentially impair the adaptability of protein-water-ligand interactions, Rossato and co-workers devised an interesting solvation algorithm, AcquaAlta, along with molecular docking.[162] The method places water molecules at the ligand-protein interface based on geometric information about water molecules, collected from the CSD. The water propensities also consider interaction energies of water to generic functional groups from ab initio calculations.[162] On 20 crystal structures used as test set, AcquaAlta succeeded in predicting $76 \%$ of water positions.

\subsection{Applications in prospective virtual screening}


This is a post print version of the article published in Curr Med Chem. 2018 May 13. doi:

$10.2174 / 0929867325666180514110824$

http://www.eurekaselect.com/162094/article

Several criteria need to be satisfied to implement the above methods in virtual screening applications. Most of the methods have shown fair to good reproducibility of experimental data, i.e. crystal-resolved water positions. Some provided solid and well-rationalised computational validations, such as 3D-RISM and WaterMap. Only the MC based methods (JAWS and GCMC) were validated on fewer experimental complexes, probably due to the relatively high computational costs of these procedures. Compatibility with apo structure could be advantageous, as the calculation can be performed just once before docking or virtual screening. However, few of the methods provided statistically significant studies on apo proteins, except WaterMap.[84]

The method also needs to be computational efficient. Calculations involving molecular simulations (WaterMap, JAWS, GCMC and related methods) are much more expensive in terms of computational time. This could impair their wider application in high-throughput virtual screening, as the meticulous calculation procedure might be more suitable for later lead optimisation. The 3D-RISM method, though it may take hours when considering the whole protein, can be restricted to the binding site to improve its efficiency. Its already well standardised applications are probably related to its conveniently developed connection to the principal MD simulation packages. SZMAP1.2 calculations can take up to several CPU-hours, but it can be scaled-up drastically with MPI support, if the user can get access to large calculation resources.

Empirical methods seem fair starting points if high-resolution crystal structures are available. This is particularly true for both HINT and WaterScore methods, as both require pre-deposited water positions to evaluate on. However, HINT does not restrict the hydration sites to be experimentally determined. WaterDock could be a potentially quick estimator of hydration sites for virtual screening. Nonetheless, its application in a real-case setting is yet to be validated. Summaries of the above methods are shown in Tables 1 and 2. 
This is a post print version of the article published in Curr Med Chem. 2018 May 13. doi:

$10.2174 / 0929867325666180514110824$

http://www.eurekaselect.com/162094/article

Table 1. The major reviewed methods for explicit water evaluation and prediction

\begin{tabular}{|c|c|c|c|c|c|}
\hline Method & Theory in brief & $\begin{array}{l}\text { Experimental } \\
\text { data? }\end{array}$ & $\begin{array}{l}\text { Apo } \\
\text { structure? }\end{array}$ & Availability* & Ref. \\
\hline Consolv & $\begin{array}{l}\text { Knowledge-based: the number } \\
\text { of closest protein atoms, the } \\
\text { hydrophilicity of the hydration } \\
\text { site, the number of water- } \\
\text { protein hydrogen bonds, and B- } \\
\text { factor }\end{array}$ & B-factor & Yes & Free (SLIDE) & [29] \\
\hline WaterScore & logistic regression analysis & $\begin{array}{l}\text { B-factor, } \\
\text { resolved water } \\
\text { positions }\end{array}$ & Yes & N/A & {$[38]$} \\
\hline$H I N T$ & $\begin{array}{l}\text { A non-Newtonian force field } \\
\text { and a Rank algorithm }\end{array}$ & $\begin{array}{l}\mathrm{LogPo} / \mathrm{w} \\
\text { resolved water } \\
\text { positions }\end{array}$ & Yes & N/A & [41] \\
\hline $\begin{array}{l}\text { 3D-RISM-KH } \\
+ \text { Placevent }\end{array}$ & $\begin{array}{l}\text { Reduced Ornstein-Zernike } \\
\text { integral equation theory in } \\
\text { combination with the KH } \\
\text { closure relation, then converting } \\
\text { solvent distribution function to } \\
\text { population function and derive } \\
\text { water positions of the highest } \\
\text { likelihood }\end{array}$ & No & Yes & $\begin{array}{l}\text { Free } \\
\text { (AmberTools) }\end{array}$ & $\begin{array}{l}{[57-59]} \\
{[71]}\end{array}$ \\
\hline WaterMap & $\begin{array}{l}\text { MD simulation and modified } \\
\text { IST }\end{array}$ & No & Yes & $\begin{array}{l}\text { Purchasable } \\
\text { license } \\
\text { (Schrödinger) } \\
\end{array}$ & {$[81,82]$} \\
\hline $\begin{array}{l}\text { GIST } \\
\text { (Amber) }\end{array}$ & $\begin{array}{l}\text { MD simulation and Gridded } \\
\text { IST }\end{array}$ & No & Yes & $\begin{array}{l}\text { Free } \\
\text { (AmberTools) }\end{array}$ & [108-110] \\
\hline STOW & MD simulation and IST & No & Yes & N/A & [114] \\
\hline WATsite & $\begin{array}{l}\text { MD simulations, followed by } \\
\text { clustering and Gaussian } \\
\text { distribution analysis }\end{array}$ & No & Yes & $\begin{array}{l}\text { Free (PyMOL } \\
\text { plugin) }\end{array}$ & [119] \\
\hline$J A W S$ & $\begin{array}{l}\lambda \text {-dynamics MC simulations, } \theta \\
\text { value simulated as water- } \\
\text { likeness }\end{array}$ & No & Yes & $\begin{array}{l}\text { Free } \\
\text { (ProtoMS and } \\
\text { MCPRO) }\end{array}$ & [123] \\
\hline$G C M C+G C I$ & $\begin{array}{l}\text { Coupling to an ideal gas } \\
\text { reservoir at a constant chemical } \\
\text { potential, optimise number of } \\
\text { solvent through free energy } \\
\text { minimisation }\end{array}$ & No & Yes & $\begin{array}{l}\text { Free } \\
\text { (ProtoMS) }\end{array}$ & [128] \\
\hline SZMAP & $\begin{array}{l}\text { Semi-continuum solvation at } \\
\text { gridded points; water probe } \\
\text { interacting with both the high } \\
\text { dielectric continuum and the } \\
\text { solute(s) }\end{array}$ & No & Yes & $\begin{array}{l}\text { Purchasable } \\
\text { license } \\
\text { (OpenEye) }\end{array}$ & [148] \\
\hline $\begin{array}{l}\text { WaterDock } \\
\text { (2.0) }\end{array}$ & $\begin{array}{l}\text { Repeatedly dock a single water } \\
\text { molecule into the site of interest }\end{array}$ & No & Yes & $\begin{array}{l}\text { Free (PyMOL } \\
\text { plugin) }\end{array}$ & {$[139,147]$} \\
\hline SuperStar & $\begin{array}{l}\text { Knowledge-based: non-bonded } \\
\text { contacts }\end{array}$ & No & Yes & \begin{tabular}{lr}
\multicolumn{2}{l}{ Purchasable } \\
license & with \\
free & trial \\
$(\mathrm{CCDC})$ & \\
\end{tabular} & [152-154] \\
\hline AcquaAlta & $\begin{array}{l}\text { Water geometric information } \\
\text { from CSD and } a b \text { initio } \\
\text { calculations }\end{array}$ & No & No & N/A & [162] \\
\hline
\end{tabular}

* The software packages that the method incorporated in are shown in parentheses. 
This is a post print version of the article published in Curr Med Chem. 2018 May 13. doi:

$10.2174 / 0929867325666180514110824$

http://www.eurekaselect.com/162094/article

Table 2: Additional validation information and outcomes of the reviewed methods for explicit water evaluation and prediction

\begin{tabular}{|c|c|c|c|}
\hline Method & Test set & Validations & Prediction accuracy* \\
\hline Consolv & $\begin{array}{l}7 \text { non-homologous proteins }(67 \\
\text { active site waters) }\end{array}$ & $\begin{array}{l}\text { Percentage accuracy in total, } \\
\text { conserved and displaced } \\
\text { water + Matthews coefficient }\end{array}$ & $74.6 \%$ \\
\hline WaterScore & $\begin{array}{l}4 \text { proteins with both free and } \\
\text { complexed form of structures } \\
(\text { resolution }<2.5 \AA)\end{array}$ & $\begin{array}{l}\text { Probability calculated from } \\
\text { best logistic regression model, } \\
1 \times 10^{-20} \text { probability threshold }\end{array}$ & $67.4-71.7 \%$ \\
\hline HINT & 4 apo proteins & $\begin{array}{l}\text { Score and rank water } \\
\text { molecules in apo structures } \\
\text { and predict their role in ligand } \\
\text { binding }\end{array}$ & $76 \%$ \\
\hline $\begin{array}{l}\text { 3D-RISM-KH } \\
+ \text { Placevent }\end{array}$ & $\begin{array}{l}1 \text { complexed structure of HIV-1 } \\
\text { protease and } 2 \text { apo structures for } \\
\text { the rotor ring of F-ATP synthase }\end{array}$ & $\begin{array}{l}\text { Blind test of predicting water } \\
\text { positions }\end{array}$ & $\begin{array}{l}\text { All the important water } \\
\text { molecules were predicted }\end{array}$ \\
\hline WaterMap & $\begin{array}{l}\text { Apo binding cavities of } \\
\text { streptavidin, Cox-2, antibody } \\
\text { DB3, and HIV protease }\end{array}$ & $\begin{array}{l}\text { World energy and excessive } \\
\text { entropy estimations, and } \\
\text { water configuration analysis }\end{array}$ & N/A \\
\hline $\begin{array}{l}\text { GIST } \\
\text { (Amber) }\end{array}$ & $\begin{array}{l}\text { Cucurbit[7]uril and coagulation } \\
\text { Factor } \mathrm{Xa}\end{array}$ & $\begin{array}{l}\text { Entropy and solvation energy } \\
\text { estimations, water } \\
\text { configurations, and } \\
\text { comparison with hydration- } \\
\text { site approach (HSA) }\end{array}$ & Perform as well as HSA \\
\hline STOW & $\begin{array}{l}\text { HIV-1 protease complexed with } \\
\text { inhibitors, concanavalin A- } \\
\text { carbohydrate complexes, CypA- } \\
\text { CsA complex }\end{array}$ & Free energy contributions & N/A \\
\hline WATsite & $\begin{array}{l}\text { Factor Xa, HIV-1 protease, and } \\
\text { pcDHFR }\end{array}$ & $\begin{array}{l}\text { Pharmacophore-based virtual } \\
\text { screening using actives and } \\
\text { DUD datasets }\end{array}$ & N/A \\
\hline$J A W S$ & 5 proteins + ligands & $\begin{array}{l}\text { Identification of hydration } \\
\text { sites, occupancy probabilities, } \\
\text { and binding free energy }\end{array}$ & $\begin{array}{l}\text { Reasonable crystal water } \\
\text { position reproducibility }\end{array}$ \\
\hline$G C M C+G C I$ & $\begin{array}{l}5 \text { proteins, a mixture of apo and } \\
\text { holo structures }\end{array}$ & $\begin{array}{l}\text { Reproducibility of consensus } \\
\text { crystal water positions }\end{array}$ & $\begin{array}{l}100 \% \text { with some false } \\
\text { positives }\end{array}$ \\
\hline SZMAP & $\begin{array}{l}6 \text { proteins with } 34 \text { structures in } \\
\text { total }\end{array}$ & $\begin{array}{l}\text { Water position prediction, } \\
\text { free energy terms calculated } \\
\text { at each position, sensitivity of } \\
\text { free energy evaluation, }\end{array}$ & $\begin{array}{l}\text { More than half of the } \\
\text { crystal water molecules } \\
\text { were predicted }\end{array}$ \\
\hline $\begin{array}{l}\text { Waterdock } \\
(2.0)\end{array}$ & $\begin{array}{l}\text { A set of high resolution X-ray } \\
\text { structures, } 14 \text { structures of OppA, } \\
\text { and the Astex Diverse set }\end{array}$ & $\begin{array}{l}\text { Conerved water prediction for } \\
\text { the first two test set, and } \\
\text { hydration site prediction for } \\
\text { the third one }\end{array}$ & $\begin{array}{l}88 \%, 97 \%, \text { and } 75 \% \\
\text { respectively }\end{array}$ \\
\hline SuperStar & $\begin{array}{l}50 \quad \text { high-resolution protein } \\
\text { structures with a total of } 16,474 \\
\text { water positions }\end{array}$ & $\begin{array}{l}\text { Peaks in water propensity } \\
\text { maps to crystal resolved } \\
\text { positions }\end{array}$ & $88 \%$ \\
\hline AcquaAlta & $\begin{array}{l}20 \text { high-resolution } \\
\text { structures for bridging } \\
\text { prediction and } 12 \text { OppA } \\
\text { structures for docking assessment } \\
\end{array}$ & $\begin{array}{l}\text { Prediction in bridging water } \\
\text { and post-docking process }\end{array}$ & $\begin{array}{l}50-100 \% \text { for binding site } \\
\text { waters, and } 58.3-100 \% \\
\text { for bridging water } \\
\text { molecules }\end{array}$ \\
\hline
\end{tabular}

* Only results of water position prediction are listed.

\section{Incorporating Explicit Solvation During Docking}

Following the potentially important hydration sites been located, the successive docking procedures should be able to incorporate explicit water molecules accordingly. The treatment of water molecules during the docking process is crucial, as the initial position of waters could be far from ideal to accommodate the foreign compounds. Additionally, potential overlap could occur while the protein-ligand interaction is favoured over solvent-mediated binding. Thus, displaceability and 
This is a post print version of the article published in Curr Med Chem. 2018 May 13. doi: $10.2174 / 0929867325666180514110824$

http://www.eurekaselect.com/162094/article

positional flexibility of these water molecules should be considered by the docking software.

Moreover, the scoring of the additional water could require updates to the scoring functions. As some of them are well-characterised for biomolecules and organic compounds, they might not be as explicit-solvent-friendly. Entropy is also important for evaluating free energy contribution of water. The entropic cost of moving a bulk water to the protein was estimated to be up to $2 \mathrm{kcal} \cdot \mathrm{mol}^{-1}$ at $300 \mathrm{~K}$.[163] This is far from trivial comparing to a solvent free energy benefit of -3.1 to $-1.9 \mathrm{kcal} \cdot \mathrm{mol}^{-1}$ for a single water molecule, calculated from two well studied biomolecular complexes. [99] Finally, other requirements might also be specifically adapted to the strategy taken for including water molecules in docking. Hereafter, we review the docking software that satisfy the above criteria to some extent. We hope this will provide useful information for medicinal chemists upon choice making, and insights for computational developers and chemists to design improved protocols and methods.

\subsection{Methods adapted to docking with explicit hydration}

Schrödinger[83] has developed WScore and WaterMap methods, both incorporated in its multi-stage systematic pose sampling methodology, $[84,85,164]$ for a more accurate scoring of docked complexes. To include protein flexibility, Repasky and co-workers introduced an ensemble docking protocol[84] in addition to the growing algorithm of relevant side chain in Glide.[164] The growing algorithm already included partial protein flexibility at binding site. The updated protocol uses multiple conformations of receptors from crystal structures and docks all ligands into each structure.[84] However, it is principally feasible to use receptor structures from alternative sources, such as clustered conformations from MD simulations. This can further improve the ligand adaptability in the binding pocket. The best scored pose is taken across the ensemble. A penalty is also added if the best score is considerably better than those of other poses. In addition, water reorganisation upon ligand binding is also considered by sampling on a grid. Glide XP,[164] the scoring function that WScore derived from, includes special rewarding terms upon replacement of solvent by ligand at the binding site. Such mechanism works like the direct penalisation of bound water molecules. The scoring function is also improved with multiple modified/added terms and penalties, in comparison to Glide XP. WaterMap is applied to identify tightly bound water molecules in multiple biomolecular systems. The combination of WaterMap and WScore provided decent improvements in both ROC AUC and enrichment factors in virtual screenings of actives against universal decoys in various systems.[84] However, to our knowledge, no prospective studies were reported so far including the application of the full tandem of WaterMap followed by WScore evaluation. Notably, efficiency is a fatal drawback of the method as MD simulations are still an essential sampling method for the IST analysis. It was reported that a WaterMap calculation for one ligand-complex can take more than 30 hours on $2.2 \mathrm{GHz} 8$-core processors.[85]

Spatial flexibility of explicit water molecules can also be modelled by considering them as additional ligands or parts of the ligands. $\operatorname{GOLD}[36,165]$ implements the flexibility using the former method. The program uses an "on-and-off" strategy to account for water occupancy.[166] Free rotation of water molecules is also included 
This is a post print version of the article published in Curr Med Chem. 2018 May 13. doi:

$10.2174 / 0929867325666180514110824$

http://www.eurekaselect.com/162094/article

in the $G O L D$ docking genetic algorithm, but with fixed translation. Therefore, the position of waters is user-defined, which requires sufficient knowledge about the water network in the binding site. Moreover, the scoring functions, Goldscore and Chemscore, were updated accordingly. The rigid-body entropy of water is included by an additional score penalty with an optimised constant value. Additional binding affinity terms for water molecules are added in the same functional forms to the regular protein-ligand interaction. Furthermore, interactions of each water molecule to other preserved ones are also included. The method reached a 93\% successful prediction of the role of water at the binding site, either mediating ligand-to-protein interactions or displaced. Improvements in the prediction of binding mode were also observed at the validation stage.

Multiple studies adopted GOLD with explicit hydration into applied molecular docking projects.[167-171] More intriguingly, its application in virtual screening has also been explored. Murray and co-workers combined the virtual screening process with NMR experiments for fragment-based lead development of heat shock protein 90 (Hsp90).[172] Four hits were identified and validated with crystallographic structures. The binding modes were also compared to crystal structures of known active compounds targeting Hsp90 and have shown a good correlation in protein-ligand contacts. One fragment was further optimised into a lead compound with low nM activity in cells. Other retrospective studies were also conducted to validate the screening performance in Cytochrome P450 1A2[173] and RNA.[174]

RosettaLigand[175] uses a multi-stage docking protocol based on MC search with full ligand and protein flexibility enabled. The water molecules at the interface can be considered as protein-centric or ligand-centric.[176] The two methods differ in the way water is treated; the former includes water movement independently from the ligand while the latter has an initial stage where water molecules move in accordance with the ligand. Additional water translation and rotation cycles are also included. However, no solvent-specific scoring adjustments are included. The force-field-based scoring function includes a desolvation energy calculated using an implicit solvent model, and the weighting factor is well-characterised for protein-ligand complexes with no explicit solvent.[175,177] Hence, the effect of including water molecules for scoring is undefined. For both the water docking methods, the author demonstrated improvements in both pose prediction and ranking.

Flexibility of explicit water molecules can be included by linking them to ligands. Both Molegro Virtual Docker (MVD)[178] and AutoDock[179] approached explicit hydration docking from this viewpoint. In both methods, water molecules are attached to the ligand molecules through hydrogen bonding. Thus, the ligands are solvated prior to docking. In $M V D$, attached water molecules (AWM) are added to the ligand according to the hydrogen bond donor/acceptor and hybridisation properties of the heavy atoms they are going to be attached at.[180] The bond distances (2.8 $⿱$ ) $)$ and angles are set at fixed values. Full flexibility is applied to the ligand and to all AWMs during the docking process, while the receptor is kept rigid. Ligand poses are characterised by positions, orientations, and torsional angles, with AWMs added to the torsion tree model with a newly defined hydrogen-bond edge. Any AWM with positive energy contribution is ignored. An additional rigid-body entropic penalty is 
This is a post print version of the article published in Curr Med Chem. 2018 May 13. doi:

$10.2174 / 0929867325666180514110824$

http://www.eurekaselect.com/162094/article

added at a constant value for each preserved water molecule after the docking run. The method provided a 50\% success rate for the 12 tested complexes. This improved to $67 \%$ when the top 5 poses were considered. Paulson and colleagues also adopted the same philosophy to include explicit hydration in Glide.[83,181] Computational investigations suggested that at least two water molecules were required to mediate interactions between thapsigargin and sarco/endoplasmic reticulum calcium ATPase.[181] Standard docking procedures failed to reproduce the correct orientation of the ligand.

Similarly to $M V D$, the attachment manoeuvre of water molecules in AutoDock occurs by saturating all the hydrogen bond donors and acceptors on the ligand molecule.[182] However, a slightly larger H-bond distance (3.0 $⿱$ ) $)$ and a set of empirical values for bond angles are used. The water molecules are represented by a neutrally charged spherical pseudoatom (W atom) combining hydrogen bond acceptor and donor properties. Whether a water molecule is displaced or conserved is continuously evaluated during the docking process by both the enthalpy and entropic contributions. The energy contribution of each $\mathrm{W}$ atom consists of weighted van der Waals and hydrogen bond enthalpies, and desolvation entropy. The authors validated the method on 221 complexes of various sizes, obtaining an increase of $11.7 \%$ in the accuracy of binding pose predictions compared to docking without water. A standardized protocol to perform docking in the presence of explicit water was also published recently.[183] Similar to previous methods, the later applications in molecular docking were mainly incurred with binding mode predictions.[184-188]

A special treatment of additional explicit solvent was also developed in FlexX. The software applies an incremental construction docking algorithm as its main implementation method.[32,189] The water molecules are incorporated using the particle concept as an extension to the original FlexX docking procedures.[190] The type and number of interactions are predefined for each particle, with restrained orientation of interactions during docking and penalised scoring in the final outcome. The initial hydration sites are approximated through a clustering analysis[191] and ghost particles are added. During docking, a ghost is converted to a particle (i.e. a water particle) if an interaction with ligand occurs. Conversely, overlapping particles are removed. If one particle has a vacant interaction, a penalty is added implicitly including the rigid-body entropy loss. The method was tested out on 200 complexes from the PDB. Minor improvements in docking were observed, but several correct predictions in the binding mode were still achieved, including the important water molecules in HIV-1 protease.

\subsection{Applications in prospective virtual screening}

A synopsis of the docking methods discussed above is reported in Table 3. Most of the methods presented satisfy the criteria to include explicit hydration in docking suggested earlier, with one exception: RosettaLigand does not include any updated enthalpic or entropic terms for water molecules. For a method that uses a force-fieldbased scoring function with a fitted desolvation from implicit solvent, its performance in binding energy evaluation remains unclear. 
This is a post print version of the article published in Curr Med Chem. 2018 May 13. doi:

$10.2174 / 0929867325666180514110824$

http://www.eurekaselect.com/162094/article

Table 3. The reviewed docking software including explicit water molecules

\begin{tabular}{|c|c|c|c|c|c|c|}
\hline Method & $\begin{array}{l}\text { Water } \\
\text { incorporation } \\
\text { strategy }\end{array}$ & $\begin{array}{l}\text { Protein } \\
\text { Flexibility }\end{array}$ & $\begin{array}{l}\text { Water } \\
\text { Flexibility }\end{array}$ & $\begin{array}{l}\text { Enthalpy/ } \\
\text { Entropy }\end{array}$ & Availability & Ref. \\
\hline $\begin{array}{l}\text { WaterMap + } \\
\text { WScore }\end{array}$ & $\begin{array}{l}\text { Simultaneous } \\
\text { multi-stage } \\
\text { docking of water } \\
\text { molecule on a } \\
\text { grid }\end{array}$ & $\begin{array}{l}\text { Structure } \\
\text { ensemble, } \\
\text { side chain } \\
\text { growing } \\
\text { algorithm } \\
\end{array}$ & $\begin{array}{l}\text { Reorganisation } \\
\text { on a grid }\end{array}$ & $\begin{array}{l}\text { Rewarding } \\
\text { ligand-protein } \\
\text { interactions }\end{array}$ & $\begin{array}{l}\text { Purchasable } \\
\text { license } \\
\text { (Schrödinger) }\end{array}$ & $\begin{array}{l}{[81,82],} \\
{[84,85]}\end{array}$ \\
\hline$G O L D$ & $\begin{array}{l}\text { Independent from } \\
\text { ligand and } \\
\text { protein, } \\
\text { additional water } \\
\text { occupancy and } \\
\text { rotation added to } \\
\text { docking } \\
\text { algorithm }\end{array}$ & $\begin{array}{l}\text { Partial } \\
\text { flexibility }\end{array}$ & $\begin{array}{l}\text { On-and-off, } \\
\text { free rotation, } \\
\text { fixed } \\
\text { translation }\end{array}$ & $\begin{array}{l}\text { Constant } \\
\text { score penalty } \\
\text { for rigid-body } \\
\text { entropy }\end{array}$ & \begin{tabular}{ll}
\multicolumn{2}{l}{ Purchasable } \\
license & with \\
free & trial \\
(CCDC) &
\end{tabular} & [166] \\
\hline \multirow[b]{2}{*}{ RossetaLigand } & $\begin{array}{l}\text { Protein-centric: } \\
\text { water molecules } \\
\text { move } \\
\text { independently to } \\
\text { ligand }\end{array}$ & $\begin{array}{l}\text { Full } \\
\text { flexibility }\end{array}$ & Full flexibility & \multirow[b]{2}{*}{$\begin{array}{l}\text { No specific } \\
\text { treatments }\end{array}$} & \multirow[b]{2}{*}{$\begin{array}{l}\text { Free* }^{*} \\
\text { (Rosetta) }\end{array}$} & \multirow[b]{2}{*}{ [176] } \\
\hline & $\begin{array}{l}\text { Ligand-centric: } \\
\text { water molecules } \\
\text { move with ligand } \\
\text { during low } \\
\text { resolution } \\
\text { sampling, then } \\
\text { independently } \\
\text { during high } \\
\text { resolution } \\
\text { sampling }\end{array}$ & $\begin{array}{l}\text { Full } \\
\text { flexibility }\end{array}$ & Full flexibility & & & \\
\hline$M V D$ & $\begin{array}{lr}\text { Ligand } & \text { pre- } \\
\text { solvated } & \text { with } \\
\text { water molecules. } & \\
\text { Extended ligand } \\
\text { torsional tree } \\
\text { model for water } \\
\text { in guided } \\
\text { differential } \\
\begin{array}{l}\text { evolutionary } \\
\text { algorithm } \\
\text { MVD of }\end{array} \\
\end{array}$ & Rigid & Full flexibility & $\begin{array}{l}\text { As ligand, } \\
\text { water } \\
\text { attached to } \\
\text { ligand } \\
\text { through } \\
\text { hydrogen } \\
\text { bonding, } \\
\text { constant } \\
\text { rigid-body } \\
\text { entropic } \\
\text { penalty } \\
\end{array}$ & $\begin{array}{l}\text { Purchasable } \\
\text { license with } \\
\text { free trial** }\end{array}$ & [180] \\
\hline AutoDock & $\begin{array}{l}\text { Ligand pre- } \\
\text { solvated with } \\
\text { water molecules. } \\
\text { Special grid map } \\
\text { of water-protein } \\
\text { interaction for } \\
\text { Lamarckian } \\
\text { Genetic } \\
\text { Algorithm }\end{array}$ & Rigid & Full flexibility & $\begin{array}{l}\text { Van der } \\
\text { Waals and } \\
\text { hydrogen } \\
\text { bond } \\
\text { enthalpies, } \\
\text { desolvation } \\
\text { entropy }\end{array}$ & Free & [182] \\
\hline FlexX & $\begin{array}{l}\text { The particle } \\
\text { concept: water } \\
\text { "particles" } \\
\text { updated at each } \\
\text { phase of the } \\
\text { docking process }\end{array}$ & Rigid & $\begin{array}{l}\text { Removable, } \\
\text { full flexibility }\end{array}$ & $\begin{array}{l}\text { Geometry } \\
\text { dependent } \\
\text { scoring, } \\
\text { implicit } \\
\text { penalty of } \\
\text { rigid-body } \\
\text { entropy }\end{array}$ & $\begin{array}{l}\text { Purchasable } \\
\text { license }\end{array}$ & [190] \\
\hline
\end{tabular}

* RosettaLigand is now included in RosettaScripts.

** Qiagen Bioinformatics has stopped maintenances of $M V D$ after version 6.0.1. A new CLC Drug Design Workbench was developed in replacement. 
This is a post print version of the article published in Curr Med Chem. 2018 May 13. doi:

$10.2174 / 0929867325666180514110824$

http://www.eurekaselect.com/162094/article

Current applications of these water-incorporating methods in real life virtual screening are still barren. One successful drug discovery project using GOLD was reported, but in combination with NMR screening re-evaluation.[172] The majority of studies, as reviewed above, are limited to molecular docking and, occasionally, lead optimisation. This lack of confidence is probably due to the acceptable performance of the still developing conventional docking methodologies, as well as concerns regarding the potential impairment on computational efficiency. Most methods indeed increase computational expenses drastically. The MD simulation phase in WaterMap makes the Glide water-docking protocol hardly feasible for virtual screenings where large computational resources are not accessible. Same goes for RosettaLigand due to the inclusion of multiple stages of MC simulation and energy minimisation. Nonetheless, with the improving in computational power, the drawbacks due to efficiency impairments will become less significant.

GOLD could be a good option if prior knowledge of water network within the binding site has already been acquired. With the water-incorporating strategy of the method, there is likely a limit on the number of water molecules that can be considered without increasing the computational time considerably. An analysis of protein-ligand complexes in PDB suggested that an average of 4.6 water molecules are involved in the bridging process.[8] This might provide some optimism toward a wider application of the method in virtual screening. Combinations of the GOLD docking with the water selection or prediction methods discussed in the early sections are also worth for further investigations.

\section{MD-based Binding Free Energy Calculation with Explicit Solvent}

MD simulations are often exploited to refine the docking poses, since they can include explicit solvation and full protein flexibility. Moreover, the post-processing of MD trajectories can be applied to compute relative binding energies, for instance rescoring results of a previous docking run. In the process of ligand recognition and, consequently, in drug design, the flexibility of proteins plays a crucial role. When a ligand binds to a protein, the receptor can undergo a delicate structural fitting process (i.e. the induced-fit effect), thus resulting in a tightly bound complex. Although multiple docking methods have implemented full or partial receptor flexibility, the treatment is still rudimental compared to MD simulations.[192-197]

Being computationally more expensive than docking, MD-based binding predictions are currently possible only in medium to low throughput screening.[12] However, rigorous MD methods such as alchemical transformations are often used to explain $a$ posteriori the role played by water in protein-ligand binding.

Double-decoupling[136,198] and free energy perturbation (FEP) $[199,200]$ are the most widely used techniques to dynamically evaluate the role of specific water molecules upon ligand binding. These methods are based on MD and statistical mechanics and belong to the alchemical free energy calculations,[201] in which the absolute or relative binding energies of a molecule are computed by "switching it off" from its surrounding, or by converting it to related species, respectively. Consequently, both double-decoupling and FEP can be applied to evaluate the free energy of binding of a water molecule into a protein binding site. In the first method, 
This is a post print version of the article published in Curr Med Chem. 2018 May 13. doi: $10.2174 / 0929867325666180514110824$

http://www.eurekaselect.com/162094/article

the electrostatic and van der Waals interactions of the water molecule with the surroundings are gradually switched off during two sets of simulations: one for transferring the water from bulk to the gas phase, and the other for transferring the water from the protein binding pocket to the gas phase.[136,198] Since this method is rather time-consuming, its application is only feasible when dealing with a very limited number of structures, where precision and detailed thermodynamic information are a priority for the calculation. This and related approaches might be helpful in retrospective studies of compounds showing peculiar structure-activity relationships.

FEP methods allow the computation of the free energy of binding through finite or infinitesimal alchemical changes of the system energy function.[199] Like doubledecoupling, these methods are very accurate but extremely time-consuming. However, recent studies involving the combination of FEP and replica exchange solute tempering methods (FEP+) demonstrated the applicability and the utility of this technique in the drug discovery process.[202-204] When simulations are conducted in explicit solvent, or if important water molecules are retained during the FEP step, this approach can consider the contribution of water to the binding free energy. For example, Ciordia et al. have recently conducted both retrospective and prospective evaluations of binding energies to optimize a novel series of amidine containing spirocyclic BACE1 inhibitors.[204] During the FEP analyses, conserved crystallographic waters were kept in the binding site and their contribution to the binding energy was included in the calculation. Alternatively, Lesenlink et al. used WaterMap to generate water molecules to be considered in FEP+ calculations to predict the binding affinities of 45 ligands to four GPCRs.[205] In another work, classical MD and FEP calculations in explicit TIP3P water were performed to identify new spleen tyrosine kinase inhibitors.[206]

Another renowned method to predict relative binding energies is the molecular mechanics Poisson-Boltzmann surface area (MM-PBSA) approach,[207,208] or its approximation using Generalized Born (MM-GBSA). The method is a good trade-off between accuracy and efficiency.[174,209-214] MM-PB/GBSA is based on the assumption that the solvent can be macroscopically described as a continuum dielectric medium.[215] Nevertheless, "bulk-like" water and "ligand-like" water could be distinguished by keeping selected explicit solvent molecules during the MMPB/GBSA analysis.[216] This allows the contribution of water-mediated hydrogen bonds to the receptor-ligand binding energy to be considered explicitly. In some cases, this approach satisfied the expectations,[217-222] but sometimes it revealed to be useless or even detrimental.[223,224]

A possible source of uncertainty is given by the way in which water molecules to be included in the calculations are selected. When experimental information is available, the most intuitive approach is to include those molecules which are known to bridge the protein with one or more ligands.[221,223,224] In most of the cases, only conserved and stable water molecules are detected in crystallographic structures. For example, the experimental activity rank of three disaccharides binding the Pseudomonas aeruginosa Lectin I (PA-IL) was correctly reproduced only by including a bridging water molecule in MM-PBSA analysis.[221] However, the 
This is a post print version of the article published in Curr Med Chem. 2018 May 13. doi:

$10.2174 / 0929867325666180514110824$

http://www.eurekaselect.com/162094/article

selection of waters should be deliberated with caution, possibly considering other parameters such as the experimental B-factor,[225] hydrogen bonds, [219] or water density/occupancy analyses.[226] In a study on factor Xa complexed to six ligands, the inclusion of water molecules with oxygen B-factor lower than 100 resulted in 0.93 and 0.97 correlations between binding energies predicted by PB and GB models, respectively, and experiments. Conversely, the default implicit approach gave an inverse correlation.[225]

It should be noted that X-ray water positions can derive from the average electron density of several molecules competing for the same site.[217,219,227] For instance, a water molecule bridging the ligand to Asn722 was observed in the crystal structure of topoisomerase I in complex with topotecan (PDB code: 1K4T).[228] However, MD simulations conducted on the complex showed that the water bridge was shared principally by three water residues (Fig. 1).[217]

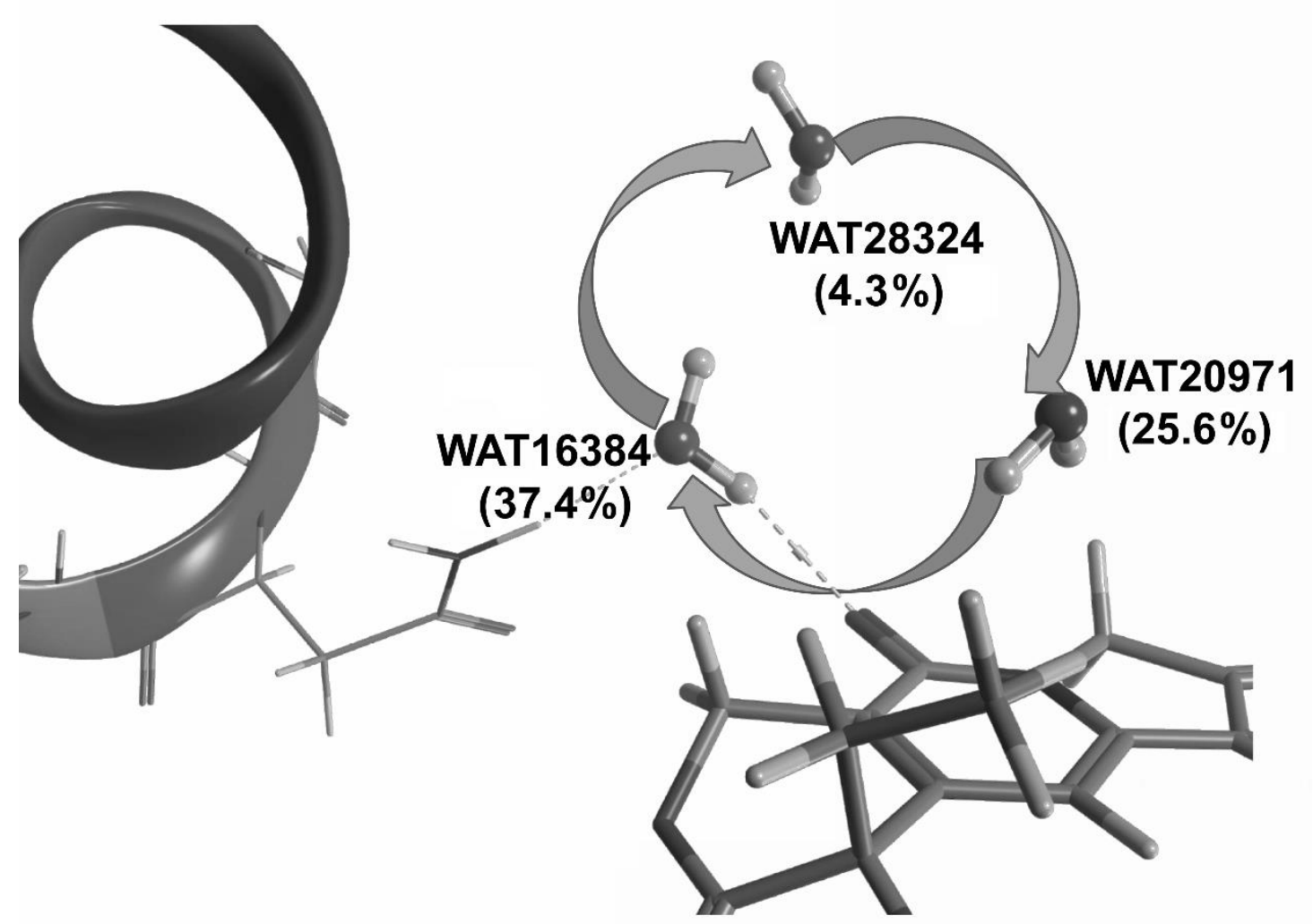

Figure 1. Representation of the swap of bridging water molecules observed during the MD simulation of topoisomerase I in complex with topotecan (PDB code 1K4T).

For this system, the inclusion of the crystallographic water in MM-PBSA or MMGBSA calculations led to a failure in ranking a series of camptothecin derivatives. However, good correlations between calculations and experiments were obtained by selecting a fixed number of water molecules that were the closest to the ligand in every frame of the MD trajectory that was going to be considered in the MM-PBSA or MM-GBSA analyses $\left(\mathrm{r}^{2}=0.51\right.$ and 0.87 for the two methods, respectively).

We developed this idea into the Nwat-MMGBSA (or Nwat-MMPBSA, depending on the nature of the implicit solvent model) protocol that, besides topoisomerase I, was 
This is a post print version of the article published in Curr Med Chem. 2018 May 13. doi:

$10.2174 / 0929867325666180514110824$

http://www.eurekaselect.com/162094/article

validated on systems such as penicillopepsin, $\alpha$-thrombin and avidin,[217] as well as on ranking different protein-protein complexes.[218] We observed an increase in the correlation between predicted binding energies and experiments of 15-50\% compared to standard MM-PB/GBSA,[217] with differences principally depending on the role played by water in the ligand-receptor interaction. Aldeghi and co-workers validated the method on 57 bromodomain systems against alchemical absolute binding free energy (ABFE) calculations.[229] The authors found that ABFE calculations still were the most accurate, but MM-PBSA including explicit ligand hydration shells was a valid alternative, especially considering the much lower computational cost. In another work, Kannan and co-workers observed that MM-PBSA calculations provided better correlations with experimental $\mathrm{IC}_{50}$ for a set of Mnk1 and Mnk2 inhibitors only when up to 10 water molecules were included in the calculation. [230] Interestingly, this number is lower than that found in our previous studies (3050),[217,218] possibly because of the smaller interface between Mnk1/Mnk2 kinases and the respective Type II inhibitors, compared to other systems. We recently integrated the Nwat-MMGBSA protocol into a complete workflow for virtual screening, automatically performing library setup, docking, ligand parameterization and MD simulations, prior to Nwat-MMGBSA rescoring.[231] The workflow was tested on two systems, AmpC $\beta$-lactamase and Rac1. Nwat-MMGBSA rescoring improved the AUC of ROC curves by 16 and $20 \%$ for the two systems, respectively, compared to standard MM-GBSA rescoring.

It should be noted that computed binding energies generally increase when explicit waters are included in MM-PB/GBSA calculations. Therefore, the out-coming energies should be interpreted as scores and not as absolute binding free energies. This is also due to the entropic term that is usually neglected in the calculation, principally due to the significant increase in computational cost required by the normal mode analysis.[225,229,232-235] Nevertheless, Aldeghi and co-workers[229] observed an improvement in correlation to experiments when entropy was considered by using a new and rather cheap approach proposed by Duan and co-workers.[236] However, the method was tested in standard MM-PBSA calculations and its combination with the inclusion of explicit waters still needs to be validated.

An attempt in using MM-GBSA to evaluate the effect of water displacement was also reported.[237] Ryde and co-workers used MM-GBSA to reproduce the binding free energies of nine phenol analogues to ferritin. All the water molecules present in the binding site were included in the calculation as part of the receptor. In addition, the effect of displaced water molecules was considered by computing the affinities of binding-site waters both before and after the ligand binding. To obtain the most accurate free energy estimations, the authors converted both the ligand and the water molecules into non-interacting ghost molecules, when unbound, to avoid the inclusion of the continuum solvent contribution to the energy. This approach then required two single-average calculations, one for the complex and one for the receptor. However, the authors evidenced the estimation of the free energy of an unbound water molecule as the principal drawback of the method. They suggested the use of the experimental value of $-47 \mathrm{~kJ} \cdot \mathrm{mol}^{-1}$ to obtain correct results on their reported example, but different values might be needed for different systems. 
This is a post print version of the article published in Curr Med Chem. 2018 May 13. doi:

$10.2174 / 0929867325666180514110824$

http://www.eurekaselect.com/162094/article

Conclusions

Modern drug design relies on the complete understanding of molecular recognitions occurring between a target and a ligand. This implies generating as much information as possible on both the structural and chemical-physical features of both partners. Nevertheless, this might not be enough, since most of the biological processes occur in water. The behaviour of water as a bulk solvent is generally considered by all computational methods applied to drug design. However, given the differences between bulk and binding site solvent properties and the role played by water in the binding process, considering water as the "third actor" in the ligand-receptor interaction is less trivial. This should indeed be done at different stages of the drug design process. First, detailed hydration pattern within the binding side can be obtained by combining experimental information with the results of MD simulations. Moreover, important water molecules might be considered in virtual screening, with the non-negligible toll taken in terms of simulation time.

Software applications such as Consolv,[29] WaterScore[38] and HINT[41] were developed to aid the selection of water molecules that might be particularly important in ligand recognition (Table 1). However, whenever experimental information on conserved water is lacking, relevant hydrations sites can also be predicted. Some predictive methods, like Placevent,[71] relies on the 3D-RISM equations, other on IST,[78-80] like the well-known WaterMap,[82] or its non-commercial alternative STOW.[114] IST-based methods require information on water dynamics, generated by a preliminary MD simulation, but MC is also feasible in water placement applications. For instance, JAWS is a rather recent MC method that works on both apo or holo proteins.[123] Modern implementations of the GCMC technique can be used either as a water placement tool, or to compute the binding free energies of single or networked water molecules.[134,135] Other methods, such as WaterDock[139,147] or $S Z M A P[148]$ can be used to place water in a putative binding site before attempting a drug design study or a virtual screening.

Relevant docking procedures with the option of incorporating explicit solvation were also discussed in this review (Table 2), together with some applications in drug design. $G O L D[36,165]$ is one of the most widely applied tools with robust applications and good successful rates in hydrated docking. It models water molecules as additional ligands and uses a "on-and-off" strategy and additional score penalty to evaluate water displacement.[166] Schrödinger[83] incorporated its WScore and WaterMap methods in a multi-stage methodology to score docking complexes.[84,85,164] RosettaLigand performs a MC search and proceed in a way either water motions are more connected to the receptor or the ligand.[175] FlexX treats water molecules as additional particles, as an extension to its original procedure.[190] Other packages, including AutoDock[179] and MVD,[178] can tackle explicit hydration by attaching water to the ligand molecules through hydrogen bonding.[180]

Finally, this review also covered the use of MD simulations to elucidate questions related to the active presence of water at binding interfaces. Indeed, the conformational space accessed by the receptor, ligand and solvent can be explored by 
This is a post print version of the article published in Curr Med Chem. 2018 May 13. doi:

$10.2174 / 0929867325666180514110824$

http://www.eurekaselect.com/162094/article

MD simulations more extensively than by docking. Moreover, the stability of water mediated interactions can be investigated and their contribution to binding explicitly evaluated. Alchemical transformations are the method of choice whenever precise and accurate thermodynamic information are desired.[136,198-200] Conversely, when a trade-off between speed and accuracy is needed, methods derived from the popular MM-PBSA technique can also be used to improve the scoring of ligands whose binding is actively facilitated by water.[238,237] Since computationally demanding, MD methods are still confined to the evaluation of a limited number of cases, but the fast development of computer hardware will probably lead to wider applications, potentially in real life drug discovery projects.

\section{List of Abbreviations}

$\mathrm{ABFE}=$ Absolute binding free energy

$\mathrm{AUC}=$ Area under the curve

$\mathrm{AWM}=$ attached water molecules

$\mathrm{CSD}=$ Cambridge structural database

$\mathrm{FEP}=$ Free energy perturbation

$\mathrm{GB}=$ Generalized Born

GIST $=$ Grid inhomogeneous solvation theory

GCMC $=$ Grand canonical Monte Carlo

$\mathrm{GCI}=$ Grand canonical integration

IST $=$ Inhomogeneous solvation theory

$\mathrm{MC}=$ Monte Carlo

$\mathrm{MD}=$ Molecular dynamics

$\mathrm{MM}=$ Molecular mechanics

MM-GBSA = Molecular mechanics - Generalized Born Surface Area

MM-PBSA = Molecular Mechanics - Poisson Boltzmann Surface Area

MPI $=$ Message passing interface

NMR = Nuclear magnetic resonance

$\mathrm{PB}=$ Poisson Boltzmann

$\mathrm{PDB}=$ Protein data bank

RISM = reference interaction site model

3D-RISM-KH = three-dimensional RISM with the closure relation by Kovalenko and Hirata

ROC $=$ Receiver operating characteristic 
This is a post print version of the article published in Curr Med Chem. 2018 May 13. doi:

$10.2174 / 0929867325666180514110824$

http://www.eurekaselect.com/162094/article

Conflict of Interest

The authors declare no conflict of interest.

\section{Acknowledgements}

Xiao Hu is supported by the European Union's Horizon 2020 research and innovation programme under the Marie Skłodowska-Curie ITN-European Joint Doctorate grant agreement No. 675527 MOGLYNET programme in Drug Discovery and Development.

\section{References}

[1] Bruno, A.; Costantino, G.; Sartori, L.; Radi, M. The in Silico Drug Discovery Toolbox: Applications in Lead Discovery and Optimization. Curr. Med. Chem. 2017.

[2] Vilar, S.; Sobarzo-Sanchez, E.; Santana, L.; Uriarte, E. Molecular Docking and Drug Discovery in $\beta$-Adrenergic Receptors. Curr. Med. Chem. 2017, 24 (39), 4340-4359.

[3] Maheswari, N.; Karthikeyan, C.; Trivedi, P.; Moorthy, N. S. Recent Advances in Protein Tyrosine Phosphatase 1B Targeted Drug Discovery for Type II Diabetes and Obesity. Curr. Drug Targets 2017, 18 (999), 1-1.

[4] Scotti, L.; T. Scotti, M. Editorial: Multi-Target in Computer-Aided Drug Design Studies. Curr. Drug Targets 2017, 18 (5), 498-499.

[5] Abdolmaleki, A.; Ghasemi, J.; Ghasemi, F. Computer Aided Drug Design for Multi-Target Drug Design: SAR /QSAR, Molecular Docking and Pharmacophore Methods. Curr. Drug Targets 2017, 18 (5), 556-575.

[6] Hendlich, M.; Bergner, A.; Günther, J.; Klebe, G. Relibase: Design and Development of a Database for Comprehensive Analysis of Protein-Ligand Interactions. J. Mol. Biol. 2003, 326 (2), 607-620.

[7] Günther, J.; Bergner, A.; Hendlich, M.; Klebe, G. Utilising Structural Knowledge in Drug Design Strategies: Applications Using Relibase. J. Mol. Biol. 2003, 326 (2), 621-636.

[8] Lu, Y.; Wang, R.; Yang, C. Y.; Wang, S. Analysis of Ligand-Bound Water Molecules in High-Resolution Crystal Structures of Protein-Ligand Complexes. J. Chem. Inf. Model. 2007, 47 (2), 668-675.

[9] Bissantz, C.; Kuhn, B.; Stahl, M. A Medicinal Chemist's Guide to Molecular Interactions. J. Med. Chem. 2010, 53 (14), 5061-5084.

[10] Bodnarchuk, M. S. Water, Water, Everywhere... It's Time to Stop and Think. Drug Discov. Today 2016, 21 (7), 1139-1146.

[11] Yang, Y.; Lightstone, F. C.; Wong, S. E. Approaches to Efficiently Estimate Solvation and Explicit Water Energetics in Ligand Binding: The Use of WaterMap. Expert Opin. Drug Discov. 2013, 8 (3), 277-287.

[12] de Beer, S.; Vermeulen, N.; Oostenbrink, C. The Role of Water Molecules in Computational Drug Design. Curr. Top. Med. Chem. 2010, 10 (1), 55-66. 
This is a post print version of the article published in Curr Med Chem. 2018 May 13. doi: $10.2174 / 0929867325666180514110824$

http://www.eurekaselect.com/162094/article

[13] Zhang, X.; Stratton, C. F.; Li, H.; Kaur, T.; Amin, A. High Affinity Inha Inhibitors with Activity against Drug-Resistent Strains of Mycobacterium Tuberculosis. ACS Chem. Biol. 2006, 1 (1), 43-53.

[14] Howard, E. I.; Sanishvili, R.; Cachau, R. E.; Mitschler, A.; Chevrier, B.; Barth, P.; Lamour, V.; Zandt, M. Van; Sibley, E.; Bon, C.; Moras, D.; Schneider, T. R.; Joachimiak, A.; Podjarny, A. Ultrahigh Resolution Drug Design I : Details of Interactions in Human Aldose Reductase - Inhibitor Complex at 0 . $66 \AA$. Proteins 2004, 55, 792-804.

[15] Wang, Y.; Freedberg, D. I.; Wingfield, P. T.; Stahl, S. J.; Kaufman, J. D.; Kiso, Y.; Bhat, T. N.; Erickson, J. W.; Torchia, D. A. Bound Water Molecules at the Interface between the HIV-1 Protease and a Potent Inhibitor, KNI-272, Determined by NMR. J. Am. Chem. Soc. 1996, 118 (49), 12287-12290.

[16] Fornabaio, M.; Spyrakis, F.; Mozzarelli, A.; Cozzini, P.; Abraham, D. J.; Kellogg, G. E. Simple, Intuitive Calculations of Free Energy of Binding for Protein-Ligand Complexes. 3. The Free Energy Contribution of Structural Water Molecules in HIV-1 Protease Complexes. J. Med. Chem. 2004, 47 (18), 4507-4516.

[17] Kageyama, S.; Mimoto, T.; Murakawa, Y.; Nomizu, M.; Ford, H.; Shirasaka, T.; Gulnik, S.; Erickson, J.; Takada, K.; Hayashi, H. In Vitro Anti-Human Immunodeficiency Virus (HIV) Activities of Transition State Mimetic HIV Protease Inhibitors Containing Allophenylnorstatine. Antimicrob. Agents Chemother. 1993, 37 (4), 810-817.

[18] Baldwin, E. T.; Bhat, T. N.; Gulnik, S.; Liu, B.; Topol, I. A.; Kiso, Y.; Mimoto, T.; Mitsuya, H.; Erickson, J. W. Structure of HIV-1 Protease with KNI-272, a Tight-Binding Transition-State Analog Containing Allophenylnorstatine. Structure 2017, 3 (6), 581-590.

[19] Lam, P. Y. S.; Jadhav, P. K.; Eyermann, C. J.; Hodge, C. N.; Ru, Y.; Bacheler, L. T.; Meek, J. L.; Otto, M. J.; Rayner, M. M.; Wong, Y. N.; Chang, C.-H.; Weber, P. C.; Jackson, D. A.; Sharpe, T. R.; Erickson-Viitanen, S. Rational Design of Potent, Bioavailable, Nonpeptide Cyclic Ureas as HIV Protease Inhibitors. Science 1994, 263 (5145), 380-384.

[20] Grzesiek, S.; Bax, A.; Nicholson, L. K.; Yamazaki, T.; Wingfield, P.; Stahl, S. J.; Eyermann, C. J.; Torchia, D. A.; Hodge, C. N. NMR Evidence for the Displacement of a Conserved Interior Water Molecule in HIV Protease by a Non-Peptide Cyclic Urea-Based Inhibitor. J. Am. Chem. Soc. 1994, 116 (4), 1581-1582.

[21] Berman, H. M.; Westbrook, J.; Feng, Z.; Gilliland, G.; Bhat, T. N.; Weissig, H.; Shindyalov, I. N.; Bourne, P. E. The Protein Data Bank. Nucleic Acids Res. 2000, 28 (1), 235-242.

[22] Groom, C. R.; Bruno, I. J.; Lightfoot, M. P.; Ward, S. C. The Cambridge Structural Database. Acta Crystallogr. Sect. B 2016, 72 (2), 171-179.

[23] Benson, M. L.; Smith, R. D.; Khazanov, N. A.; Dimcheff, B.; Beaver, J.; Dresslar, P.; Nerothin, J.; Carlson, H. A. Binding MOAD, a High-Quality Protein-Ligand Database. Nucleic Acids Res. 2008, 36 (Database issue), D674- 
This is a post print version of the article published in Curr Med Chem. 2018 May 13. doi: $10.2174 / 0929867325666180514110824$

http://www.eurekaselect.com/162094/article

8.

[24] Ahmed, A.; Smith, R. D.; Clark, J. J.; Dunbar, J. B.; Carlson, H. A.; Carlson, H. A. Recent Improvements to Binding MOAD: A Resource for ProteinLigand Binding Affinities and Structures. Nucleic Acids Res. 2015, 43 (Database issue), D465-9.

[25] Liu, Z.; Li, Y.; Han, L.; Li, J.; Liu, J.; Zhao, Z.; Nie, W.; Liu, Y.; Wang, R. PDB-Wide Collection of Binding Data: Current Status of the PDBbind Database. Bioinformatics 2015, 31 (3), 405-412.

[26] Wang, R.; Fang, X.; Lu, Y.; Wang, S. The PDBbind Database: Collection of Binding Affinities for Protein-Ligand Complexes with Known ThreeDimensional Structures. J. Med. Chem. 2004, 47 (12), 2977-2980.

[27] Gilson, M. K.; Liu, T.; Baitaluk, M.; Nicola, G.; Hwang, L.; Chong, J. BindingDB in 2015: A Public Database for Medicinal Chemistry, Computational Chemistry and Systems Pharmacology. Nucleic Acids Res. 2016, 44 (D1), D1045-D1053.

[28] Liu, T.; Lin, Y.; Wen, X.; Jorissen, R. N.; Gilson, M. K. BindingDB: A WebAccessible Database of Experimentally Determined Protein-Ligand Binding Affinities. Nucleic Acids Res. 2007, 35 (Database), D198-D201.

[29] Raymer, M. L.; Sanschagrin, P. C.; Punch, W. F.; Venkataraman, S.;

Goodman, E. D.; Kuhn, L. A. Predicting Conserved Water-Mediated and Polar Ligand Interactions in Proteins Using a K-Nearest-Neighbors Genetic Algorithm. J. Mol. Biol. 1997, 265 (4), 445-464.

[30] Renxiao Wang; Yipin Lu, and; Wang*, S. Comparative Evaluation of 11 Scoring Functions for Molecular Docking. 2003.

[31] Liu, J.; Wang, R. Classification of Current Scoring Functions. J. Chem. Inf. Model. 2015, 55 (3), 475-482.

[32] Rarey, M.; Kramer, B.; Lengauer, T.; Klebe, G. A Fast Flexible Docking Method Using an Incremental Construction Algorithm. J. Mol. Biol. 1996, 261 (3), 470-489.

[33] Wang, R.; Lai, L.; Wang, S. Further Development and Validation of Empirical Scoring Functions for Structure-Based Binding Affinity Prediction. J. Comput. Aided. Mol. Des. 2002, 16 (1), 11-26.

[34] Richard A. Friesner, *,†; Jay L. Banks, †; Robert B. Murphy, †; Thomas A. Halgren, \$; Jasna J. Klicic, \$, Eric H. Knoll, $\uparrow$; Mee Shelley, §; Jason K. Perry, §; David E. Shaw, \#; Perry Francis, $\S$ and; Shenkint, P. S. Glide: A New Approach for Rapid, Accurate Docking and Scoring. 1. Method and Assessment of Docking Accuracy. 2004.

[35] Goodsell, D. S.; Morris, G. M.; Olson, A. J. Automated Docking of Flexible Ligands: Applications of Autodock. J. Mol. Recognit. 1996, 9 (1), 1-5.

[36] Jones, G.; Willett, P.; Glen, R. C.; Leach, A. R.; Taylor, R. Development and Validation of a Genetic Algorithm for Flexible Docking 1 1Edited by F. E. Cohen. J. Mol. Biol. 1997, 267 (3), 727-748. 
This is a post print version of the article published in Curr Med Chem. 2018 May 13. doi: $10.2174 / 0929867325666180514110824$

http://www.eurekaselect.com/162094/article

[37] Yin, S.; Biedermannova, L.; Vondrasek, J.; Dokholyan, N. V. MedusaScore: An Accurate Force Field-Based Scoring Function for Virtual Drug Screening. J. Chem. Inf. Model. 2008, 48 (8), 1656-1662.

[38] García-Sosa, A. T.; Mancera, R. L.; Dean, P. M. WaterScore: A Novel Method for Distinguishing between Bound and Displaceable Water Molecules in the Crystal Structure of the Binding Site of Protein-Ligand Complexes. J. Mol. Model. 2003, 9 (3), 172-182.

[39] García-Sosa, A. T. Hydration Properties of Ligands and Drugs in Protein Binding Sites: Tightly-Bound, Bridging Water Molecules and Their Effects and Consequences on Molecular Design Strategies. J. Chem. Inf. Model. 2013, 53 (6), 1388-1405.

[40] García-Sosa, A. T.; Mancera, R. L. Free Energy Calculations of Mutations Involving a Tightly Bound Water Molecule and Ligand Substitutions in a Ligand-Protein Complex. Mol. Inform. 2010, 29 (8-9), 589-600.

[41] Amadasi, A.; Spyrakis, F.; Cozzini, P.; Abraham, D. J.; Kellogg, G. E.; Mozzarelli, A. Mapping the Energetics of Water-Protein and Water-Ligand Interactions with the "natural" HINT Forcefield: Predictive Tools for Characterizing the Roles of Water in Biomolecules. J. Mol. Biol. 2006, 358 (1), 289-309.

[42] Chen, D. L.; Kellogg, G. E. A Computational Tool to Optimize Ligand Selectivity between Two Similar Biomacromolecular Targets. J. Comput. Aided. Mol. Des. 2005, 19 (2), 69-82.

[43] Amadasi, A.; Surface, J. A.; Spyrakis, F.; Cozzini, P.; Mozzarelli, A.; Kellogg, G. E. Robust Classification Of "relevant" water Molecules in Putative Protein Binding Sites. J. Med. Chem. 2008, 51 (4), 1063-1067.

[44] Ahmed, M. H.; Spyrakis, F.; Cozzini, P.; Tripathi, P. K.; Mozzarelli, A.; Scarsdale, J. N.; Safo, M. A.; Kellogg, G. E. Bound Water at Protein-Protein Interfaces: Partners, Roles and Hydrophobic Bubbles as a Conserved Motif. PLoS One 2011, 6 (9), e24712.

[45] Ahmed, M. H.; Habtemariam, M.; Safo, M. K.; Scarsdale, J. N.; Spyrakis, F.; Cozzini, P.; Mozzarelli, A.; Kellogg, G. E. Unintended Consequences? Water Molecules at Biological and Crystallographic Protein-Protein Interfaces. Comput. Biol. Chem. 2013, 47, 126-141.

[46] Parikh, H. I.; Kellogg, G. E. Intuitive, but Not Simple: Including Explicit Water Molecules in Protein-Protein Docking Simulations Improves Model Quality. Proteins Struct. Funct. Bioinforma. 2014, 82 (6), 916-932.

[47] Bayden, A. S.; Fornabaio, M.; Scarsdale, J. N.; Kellogg, G. E. Web Application for Studying the Free Energy of Binding and Protonation States of Protein-Ligand Complexes Based on HINT. J. Comput. Aided. Mol. Des. 2009, 23 (9), 621-632.

[48] Salsi, E.; Bayden, A. S.; Spyrakis, F.; Amadasi, A.; Campanini, B.; Bettati, S.; Dodatko, T.; Cozzini, P.; Kellogg, G. E.; Cook, P. F.; Roderick, S. L.; Mozzarelli, A. Design of O-Acetylserine Sulfhydrylase Inhibitors by 
This is a post print version of the article published in Curr Med Chem. 2018 May 13. doi: $10.2174 / 0929867325666180514110824$

http://www.eurekaselect.com/162094/article

Mimicking Nature. J. Med. Chem. 2010, 53 (1), 345-356.

[49] Mosier, P. D.; Krishnasamy, C.; Kellogg, G. E.; Desai, U. R. On the Specificity of Heparin/Heparan Sulfate Binding to Proteins. Anion-Binding Sites on Antithrombin and Thrombin Are Fundamentally Different. PLoS One 2012, 7 (11), e48632.

[50] Spyrakis, F.; Cellini, B.; Bruno, S.; Benedetti, P.; Carosati, E.; Cruciani, G.; Micheli, F.; Felici, A.; Cozzini, P.; Kellogg, G. E.; Voltattorni, C. B.; Mozzarelli, A. Targeting Cystalysin, a Virulence Factor of Treponema Denticola-Supported Periodontitis. ChemMedChem 2014, 9 (7), 1501-1511.

[51] Dellafiora, L.; Marchetti, M.; Spyrakis, F.; Orlandi, V.; Campanini, B.; Cruciani, G.; Cozzini, P.; Mozzarelli, A. Expanding the Chemical Space of Human Serine Racemase Inhibitors. Bioorganic Med. Chem. Lett. 2015, 25 (19), 4297-4303.

[52] Roberts, B. C.; Mancera, R. L. Ligand-Protein Docking with Water Molecules. J. Chem. Inf. Model. 2008, 48 (2), 397-408.

[53] Chandler, D.; Andersen, H. C. Optimized Cluster Expansions for Classical Fluids. II. Theory of Molecular Liquids. J. Chem. Phys. 1972, 57 (5), 19301937.

[54] Hirata, F.; Pettitt, B. M.; Rossky, P. J. Application of an Extended RISM Equation to Dipolar and Quadrupolar Fluids. J. Chem. Phys. 1982, 77 (1), 509520 .

[55] Hirata, F.; Rossky, P. J. An Extended Rism Equation for Molecular Polar Fluids. Chem. Phys. Lett. 1981, 83 (2), 329-334.

[56] Hirata, F.; Rossky, P. J.; Pettitt, B. M. The Interionic Potential of Mean Force in a Molecular Polar Solvent from an Extended RISM Equation. J. Chem. Phys. 1983, 78 (6), 4133-4144.

[57] Kovalenko, A.; Hirata, F. Three-Dimensional Density Profiles of Water in Contact with a Solute of Arbitrary Shape: A RISM Approach. Chem. Phys. Lett. 1998, 290 (1), 237-244.

[58] Kovalenko, A.; Hirata, F. Self-Consistent Description of a Metal-water Interface by the Kohn-Sham Density Functional Theory and the ThreeDimensional Reference Interaction Site Model. J. Chem. Phys. 1999, 110 (20), 10095-10112.

[59] Kovalenko, A. Multiscale Modeling of Solvation in Chemical and Biological Nanosystems and in Nanoporous Materials. Pure Appl. Chem. 2013, 85 (1), 159-199.

[60] Hansen, J.-P.; McDonald, I. R. Theory of Simple Liquids, 4th ed.; Academic Press, 2013.

[61] Kovalenko, A. Three-Dimensional Rism Theory for Molecular Liquids and Solid-Liquid Interfaces. In Molecular Theory of Solvation; Hirata, F., Ed.; Kluwer Academic Publishers: Dordrecht, 2003; pp 169-275.

[62] Ram, J. Equilibrium Theory of Molecular Fluids: Structure and Freezing 
This is a post print version of the article published in Curr Med Chem. 2018 May 13. doi: $10.2174 / 0929867325666180514110824$

http://www.eurekaselect.com/162094/article

Transitions. Physics Reports. North-Holland May 30, 2014, pp 121-185.

[63] Kovalenko. Molecular Theory of Solvation: Methodology Summary and Illustrations. Condens. Matter Phys. 2015, 18 (3), 32601.

[64] Yoshida, N. Role of Solvation in Drug Design as Revealed by the Statistical Mechanics Integral Equation Theory of Liquids. Journal of Chemical

Information and Modeling. American Chemical Society November 27, 2017, pp 2646-2656.

[65] Kovalenko, A.; Kobryn, A. E.; Gusarov, S.; Lyubimova, O.; Liu, X.; Blinov, N.; Yoshida, M. Molecular Theory of Solvation for Supramolecules and Soft Matter Structures: Application to Ligand Binding, Ion Channels, and Oligomeric Polyelectrolyte Gelators. Soft Matter 2012, 8 (5), 1508-1520.

[66] Yoshida, N.; Imai, T.; Phongphanphanee, S.; Kovalenko, A.; Hirata, F. Molecular Recognition in Biomolecules Studied by Statistical-Mechanical Integral-Equation Theory of Liquids. J. Phys. Chem. B 2009, 113 (4), 873-886.

[67] Phongphanphanee, S.; Yoshida, N.; Hirata, F. On the Proton Exclusion of Aquaporins: A Statistical Mechanics Study. J. Am. Chem. Soc. 2008, 130 (5), 1540-1541.

[68] Maruyama, Y.; Yoshida, N.; Hirata, F. Electrolytes in Biomolecular Systems Studied with the 3D-RISM/RISM Theory. Interdiscip. Sci. Comput. Life Sci. 2011, 3 (4), 290-307.

[69] Genheden, S.; Luchko, T.; Gusarov, S.; Kovalenko, A.; Ryde, U. An MM/3DRISM Approach for Ligand Binding Affinities. J. Phys. Chem. B 2010, 114 (25), 8505-8516.

[70] Huang, W.; Blinov, N.; Wishart, D. S.; Kovalenko, A. Role of Water in Ligand Binding to Maltose-Binding Protein: Insight from a New Docking Protocol Based on the 3D-RISM-KH Molecular Theory of Solvation. J. Chem. Inf. Model. 2015, 55 (2), 317-328.

[71] Sindhikara, D. J.; Yoshida, N.; Hirata, F. Placevent: An Algorithm for Prediction of Explicit Solvent Atom Distribution-Application to HIV-1 Protease and F-ATP Synthase. J. Comput. Chem. 2012, 33 (18), 1536-1543.

[72] Zhu, T.; Zhang, J. Z. H.; He, X. Automated Fragmentation QM/MM Calculation of Amide Proton Chemical Shifts in Proteins with Explicit Solvent Model. J. Chem. Theory Comput. 2013, 9 (4), 2104-2114.

[73] He, X.; Zhu, T.; Wang, X.; Liu, J.; Zhang, J. Z. H. Fragment Quantum Mechanical Calculation of Proteins and Its Applications. Acc. Chem. Res. 2014, 47 (9), 2748-2757.

[74] Watanabe, H. C.; Welke, K.; Sindhikara, D. J.; Hegemann, P.; Elstner, M. Towards an Understanding of Channelrhodopsin Function: Simulations Lead to Novel Insights of the Channel Mechanism. J. Mol. Biol. 2013, 425 (10), 17951814.

[75] Huang, Y.-H.; Henriques, S. T.; Wang, C. K.; Thorstholm, L.; Daly, N. L.; Kaas, Q.; Craik, D. J. Design of Substrate-Based BCR-ABL Kinase Inhibitors 
This is a post print version of the article published in Curr Med Chem. 2018 May 13. doi: $10.2174 / 0929867325666180514110824$

http://www.eurekaselect.com/162094/article

Using the Cyclotide Scaffold. Sci. Rep. 2015, 5 (1), 12974.

[76] Lu, S.; Deng, R.; Jiang, H.; Song, H.; Li, S.; Shen, Q.; Huang, W.; Nussinov, R.; Yu, J.; Zhang, J. The Mechanism of ATP-Dependent Allosteric Protection of Akt Kinase Phosphorylation. Structure 2015, 23 (9), 1725-1734.

[77] Stumpe, M. C.; Blinov, N.; Wishart, D.; Kovalenko, A.; Pande, V. S. Calculation of Local Water Densities in Biological Systems: A Comparison of Molecular Dynamics Simulations and the 3D-RISM-KH Molecular Theory of Solvation. J. Phys. Chem. B 2011, 115 (2), 319-328.

[78] Lazaridis, T. Inhomogeneous Fluid Approach to Solvation Thermodynamics. 1. Theory. J. Phys. Chem. B 1998, 102 (18), 3531-3541.

[79] Lazaridis, T.; Karplus, M. Orientational Correlations and Entropy in Liquid Water. J. Chem. Phys. 1996, 105 (10), 4294-4316.

[80] Lazaridis, T.; Paulaitis, M. E. Entropy of Hydrophobic Hydration: A New Statistical Mechanical Formulation. J. Phys. Chem. 1992, 96 (9), 3847-3855.

[81] Abel, R.; Young, T.; Farid, R.; Berne, B. J.; Friesner, R. A. Role of the ActiveSite Solvent in the Thermodynamics of Factor Xa Ligand Binding. J. Am. Chem. Soc. 2008, 130 (9), 2817-2831.

[82] Young, T.; Abel, R.; Kim, B.; Berne, B. J.; Friesner, R. A. Motifs for Molecular Recognition Exploiting Hydrophobic Enclosure in Protein-ligand Binding. Proc. Natl. Acad. Sci. 2007, 104 (3), 808-813.

[83] Schrödinger. Small-Molecule Drug Discovery Suite 2017-4. Schrödinger, LLC: New York, NY 2017.

[84] Repasky, M. P.; Murphy, R. B.; Banks, J. L.; Greenwood, J. R.; TubertBrohman, I.; Bhat, S.; Friesner, R. A. Docking Performance of the Glide Program as Evaluated on the Astex and DUD Datasets: A Complete Set of Glide SP Results and Selected Results for a New Scoring Function Integrating WaterMap and Glide. J. Comput. Aided. Mol. Des. 2012, 26 (6), 787-799.

[85] Murphy, R. B.; Repasky, M. P.; Greenwood, J. R.; Tubert-Brohman, I.; Jerome, S.; Annabhimoju, R.; Boyles, N. A.; Schmitz, C. D.; Abel, R.; Farid, R.; Friesner, R. A. WScore: A Flexible and Accurate Treatment of Explicit Water Molecules in Ligand-Receptor Docking. J. Med. Chem. 2016, 59 (9), 4364-4384.

[86] Robinson, D. D.; Sherman, W.; Farid, R. Understanding Kinase Selectivity through Energetic Analysis of Binding Site Waters. ChemMedChem 2010, 5 (4), 618-627.

[87] Higgs, C.; Beuming, T.; Sherman, W. Hydration Site Thermodynamics Explain SARs for Triazolylpurines Analogues Binding to the A2A Receptor. ACS Med. Chem. Lett. 2010, 1 (4), 160-164.

[88] Fidock, D. A. Drug Discovery: Priming the Antimalarial Pipeline. Nature. Nature Publishing Group May 20, 2010, pp 297-298.

[89] Cuny, G. D.; Yu, P. B.; Laha, J. K.; Xing, X.; Liu, J.-F.; Lai, C. S.; Deng, D. Y.; Sachidanandan, C.; Bloch, K. D.; Peterson, R. T. Structure-activity 
This is a post print version of the article published in Curr Med Chem. 2018 May 13. doi: $10.2174 / 0929867325666180514110824$

http://www.eurekaselect.com/162094/article

Relationship Study of Bone Morphogenetic Protein (BMP) Signaling Inhibitors. Bioorg. Med. Chem. Lett. 2008, 18 (15), 4388-4392.

[90] Chrencik, J. E.; Patny, A.; Leung, I. K.; Korniski, B.; Emmons, T. L.; Hall, T.; Weinberg, R. A.; Gormley, J. A.; Williams, J. M.; Day, J. E.; Hirsch, J. L.; Kiefer, J. R.; Leone, J. W.; Fischer, H. D.; Sommers, C. D.; Huang, H. C.; Jacobsen, E. J.; Tenbrink, R. E.; Tomasselli, A. G.; Benson, T. E. Structural and Thermodynamic Characterization of the TYK2 and JAK3 Kinase Domains in Complex with CP-690550 and CMP-6. J. Mol. Biol. 2010, 400 (3), 413-433.

[91] Knegtel, R. M. A.; Robinson, D. D. A Role for Hydration in Interleukin-2 Inducible T Cell Kinase (Itk) Selectivity. Mol. Inform. 2011, 30 (11-12), 950959.

[92] Beuming, T.; Che, Y.; Abel, R.; Kim, B.; Shanmugasundaram, V.; Sherman, W. Thermodynamic Analysis of Water Molecules at the Surface of Proteins and Applications to Binding Site Prediction and Characterization. Proteins Struct. Funct. Bioinforma. 2012, 80 (3), 871-883.

[93] Bortolato, A.; Tehan, B. G.; Bodnarchuk, M. S.; Essex, J. W.; Mason, J. S. Water Network Perturbation in Ligand Binding: Adenosine A2A Antagonists as a Case Study. J. Chem. Inf. Model. 2013, 53 (7), 1700-1713.

[94] Tehan, B. G.; Bortolato, A.; Blaney, F. E.; Weir, M. P.; Mason, J. S. Unifying Family A GPCR Theories of Activation. Pharmacol. Ther. 2014, 143 (1), 5160.

[95] Breiten, B.; Lockett, M. R.; Sherman, W.; Fujita, S.; Al-Sayah, M.; Lange, H.; Bowers, C. M.; Heroux, A.; Krilov, G.; Whitesides, G. M. Water Networks Contribute to Enthalpy/entropy Compensation in Protein-Ligand Binding. $J$. Am. Chem. Soc. 2013, 135 (41), 15579-15584.

[96] Kohlmann, A.; Zech, S. G.; Li, F.; Zhou, T.; Squillace, R. M.; Commodore, L.; Greenfield, M. T.; Lu, X.; Miller, D. P.; Huang, W. S.; Qi, J.; Thomas, R. M.; Wang, Y.; Zhang, S.; Dodd, R.; Liu, S.; Xu, R.; Xu, Y.; Miret, J. J.; Rivera, V.; Clackson, T.; Shakespeare, W. C.; Zhu, X.; Dalgarno, D. C. Fragment Growing and Linking Lead to Novel Nanomolar Lactate Dehydrogenase Inhibitors. $J$. Med. Chem. 2013, 56 (3), 1023-1040.

[97] Newman, A. H.; Beuming, T.; Banala, A. K.; Donthamsetti, P.; Pongetti, K.; Labounty, A.; Levy, B.; Cao, J.; Michino, M.; Luedtke, R. R.; Javitch, J. A.; Shi, L. Molecular Determinants of Selectivity and Efficacy at the Dopamine D3 Receptor. J. Med. Chem. 2012, 55 (15), 6689-6699.

[98] Abel, R.; Salam, N. K.; Shelley, J.; Farid, R.; Friesner, R. A.; Sherman, W. Contribution of Explicit Solvent Effects to the Binding Affinity of SmallMolecule Inhibitors in Blood Coagulation Factor Serine Proteases. ChemMedChem 2011, 6 (6), 1049-1066.

[99] Ohno, K.; Mori, K.; Orita, M.; Takeuchi, M. Computational Insights into Binding of Bisphosphates to Farnesyl Pyrophosphate Synthase. Curr. Med. Chem. 2011, 18 (2), 220-233.

[100] Han, S.; Zaniewski, R. P.; Marr, E. S.; Lacey, B. M.; Tomaras, A. P.; 
This is a post print version of the article published in Curr Med Chem. 2018 May 13. doi: $10.2174 / 0929867325666180514110824$

http://www.eurekaselect.com/162094/article

Evdokimov, A.; Miller, J. R.; Shanmugasundaram, V. Structural Basis for Effectiveness of Siderophore-Conjugated Monocarbams against Clinically Relevant Strains of Pseudomonas Aeruginosa. Proc. Natl. Acad. Sci. 2010, 107 (51), 22002-22007.

[101] Pearlstein, R. A.; Hu, Q. Y.; Zhou, J.; Yowe, D.; Levell, J.; Dale, B.; Kaushik, V. K.; Daniels, D.; Hanrahan, S.; Sherman, W.; Abel, R. New Hypotheses Aboutthe Structure-Function of Proprotein Convertase Subtilisin/kexin Type 9: Analysisoftheepidermalgrowth Factor-like Repeatadockingsiteusingwatermap. Proteins Struct. Funct. Bioinforma. 2010, 78 (12), 2571-2586.

[102] Beuming, T.; Farid, R.; Sherman, W. High-Energy Water Sites Determine Peptide Binding Affinity and Specificity of PDZ Domains. Protein Sci. 2009, 18 (8), 1609-1619.

[103] de Azevedo, W. F. Molecular Dynamics Simulations of Protein Targets Identified in Mycobacterium Tuberculosis. Curr. Med. Chem. 2011, 18 (9), 1353-1366.

[104] de Azevedo, W. F.; Canduri, F.; Fadel, V.; Teodoro, L. G. V. L.; Hial, V.; Gomes, R. A. S. Molecular Model for the Binary Complex of Uropepsin and Pepstatin. Biochem. Biophys. Res. Commun. 2001, 287 (1), 277-281.

[105] Cardoso Perez, P.; Caceres, R. A.; Canduri, F.; de Azevedo, W. F. Molecular Modeling and Dynamics Simulation of Human Cyclin-Dependent Kinase 3 Complexed with Inhibitors. Comput. Biol. Med. 2009, 39 (2), 130-140.

[106] Canduri, F.; Perez, P. C.; Caceres, R. A.; de Azevedo, W. F. Protein Kinases as Targets for Antiparasitic Chemotherapy Drugs. Curr. Drug Targets 2007, 8 (3), 389-398.

[107] Wang, L.; Berne, B. J.; Friesner, R. A. Ligand Binding to Protein-Binding Pockets with Wet and Dry Regions. Proc. Natl. Acad. Sci. 2011, 108 (4), 13261330.

[108] Nguyen, C. N.; Kurtzman Young, T.; Gilson, M. K. Grid Inhomogeneous Solvation Theory: Hydration Structure and Thermodynamics of the Miniature Receptor cucurbit[7]uril. J. Chem. Phys. 2012, 137 (4), 973-980.

[109] Nguyen, C. N.; Cruz, A.; Gilson, M. K.; Kurtzman, T. Thermodynamics of Water in an Enzyme Active Site: Grid-Based Hydration Analysis of Coagulation Factor Xa. J. Chem. Theory Comput. 2014, 10 (7), 2769-2780.

[110] Ramsey, S.; Nguyen, C.; Salomon-Ferrer, R.; Walker, R. C.; Gilson, M. K.; Kurtzman, T. Solvation Thermodynamic Mapping of Molecular Surfaces in Ambertools: GIST. J. Comput. Chem. 2016, 37 (21), 2029-2037.

[111] Roe, D. R.; Cheatham, T. E. PTRAJ and CPPTRAJ: Software for Processing and Analysis of Molecular Dynamics Trajectory Data. J. Chem. Theory Comput. 2013, 9 (7), 3084-3095.

[112] Morris, G. M.; Ruth, H.; Lindstrom, W.; Sanner, M. F.; Belew, R. K.; Goodsell, D. S.; Olson, A. J. Software News and Updates AutoDock4 and AutoDockTools4: Automated Docking with Selective Receptor Flexibility. J. Comput. Chem. 2009, 30 (16), 2785-2791. 
This is a post print version of the article published in Curr Med Chem. 2018 May 13. doi: $10.2174 / 0929867325666180514110824$

http://www.eurekaselect.com/162094/article

[113] Uehara, S.; Tanaka, S. AutoDock-GIST: Incorporating Thermodynamics of Active-Site Water into Scoring Function for Accurate Protein-Ligand Docking. Molecules 2016, 21 (11), 1604.

[114] Li, Z.; Lazaridis, T. Computational Drug Discovery and Design; Baron, R., Ed.; Methods in Molecular Biology; Springer New York: New York, NY, 2012; Vol. 819.

[115] Li, Z.; Lazaridis, T. Thermodynamics of Buried Water Clusters at a ProteinLigand Binding Interface. J. Phys. Chem. B 2006, 110 (3), 1464-1475.

[116] Li, Z.; Lazaridis, T. The Effect of Water Displacement on Binding Thermodynamics: Concanavalin A. J. Phys. Chem. B 2005, 109 (1), 662-670.

[117] Li, Z.; Lazaridis, T. Thermodynamic Contributions of the Ordered Water Molecule in HIV-1 Protease. J. Am. Chem. Soc. 2003, 125 (22), 6636-6637.

[118] Li, Z.; Lazaridis, T. Water at Biomolecular Binding Interfaces. Phys. Chem. Chem. Phys. 2007, 9 (5), 573-581.

[119] Hu, B.; Lill, M. A. WATsite: Hydration Site Prediction Program with PyMOL Interface. J. Comput. Chem. 2014, 35 (16), 1255-1260.

[120] Hu, B.; Lill, M. A. Protein Pharmacophore Selection Using Hydration-Site Analysis. J. Chem. Inf. Model. 2012, 52 (4), 1046-1060.

[121] López, E. D.; Arcon, J. P.; Gauto, D. F.; Petruk, A. A.; Modenutti, C. P.; Dumas, V. G.; Marti, M. A.; Turjanski, A. G. WATCLUST: A Tool for Improving the Design of Drugs Based on Protein-Water Interactions. Bioinformatics 2015, 31 (22), 3697-3699.

[122] Humphrey, W.; Dalke, A.; Schulten, K. VMD: Visual Molecular Dynamics. J. Mol. Graph. 1996, 14 (1), 33-38.

[123] Michel, J.; Tirado-Rives, J.; Jorgensen, W. L. Prediction of the Water Content in Protein Binding Sites. J. Phys. Chem. B 2009, 113 (40), 13337-13346.

[124] Jorgensen, W. L.; Tirado-Rives, J. Molecular Modeling of Organic and Biomolecular Systems Using BOSS and MCPRO. Journal of Computational Chemistry. Wiley Subscription Services, Inc., A Wiley Company December 1, 2005, pp 1689-1700.

[125] Michel, J.; Tirado-Rives, J.; Jorgensen, W. L. Energetics of Displacing Water Molecules from Protein Binding Sites: Consequences for Ligand Optimization. J. Am. Chem. Soc. 2009, 131 (42), 15403-15411.

[126] Luccarelli, J.; Michel, J.; Tirado-Rives, J.; Jorgensen, W. L. Effects of Water Placement on Predictions of Binding Affinities for p38R MAP Kinase Inhibitors. J. Chem. Theory Comput. 2010, 6 (12), 3850-3856.

[127] Cole, D. J.; Tirado-Rives, J.; Jorgensen, W. L. Enhanced Monte Carlo Sampling through Replica Exchange with Solute Tempering. J. Chem. Theory Comput. 2014, 10 (2), 565-571.

[128] Adams, D. J. Grand Canonical Ensemble Monte Carlo for a Lennard-Jones Fluid. Mol. Phys. 1975, 29 (1), 307-311. 
This is a post print version of the article published in Curr Med Chem. 2018 May 13. doi: $10.2174 / 0929867325666180514110824$

http://www.eurekaselect.com/162094/article

[129] Resat, H.; Mezei, M. Grand Canonical Ensemble Monte Carlo Simulation of the dCpG/proflavine Crystal Hydrate. Biophys. J. 1996, 71 (3), 1179-1190.

[130] Marrone, T. J.; Resat, H.; Hodge, C. N.; Chang, C. H.; McCammon, J. A. Solvation Studies of DMP323 and A76928 Bound to HIV Protease: Analysis of Water Sites Using Grand Canonical Monte Carlo Simulations. Protein Sci. 1998, 7 (3), 573-579.

[131] Speidel, J. A.; Banfelder, J. R.; Mezei, M. Automatic Control of Solvent Density in Grand Canonical Ensemble Monte Carlo Simulations. J. Chem. Theory Comput. 2006, 2 (5), 1429-1434.

[132] Malasics, A.; Gillespie, D.; Boda, D. Simulating Prescribed Particle Densities in the Grand Canonical Ensemble Using Iterative Algorithms. J. Chem. Phys. 2008, 128 (12), 124102.

[133] Ross, G. A.; Bodnarchuk, M. S.; Essex, J. W. Water Sites, Networks, and Free Energies with Grand Canonical Monte Carlo. J. Am. Chem. Soc. 2015, 137 (47), 14930-14943.

[134] Woods, C. J.; Essex, J. W.; King, M. A. Enhanced Configurational Sampling in Binding Free-Energy Calculations. J Phys Chem B 2003, 107 (49), 1371113718.

[135] Woods, C. J.; Essex, J. W.; King, M. A. The Development of ReplicaExchange-Based Free-Energy Methods. J. Phys. Chem. B 2003, 107 (49), 13703-13710.

[136] Gilson, M. K.; Given, J. A.; Bush, B. L.; McCammon, J. A. The StatisticalThermodynamic Basis for Computation of Binding Affinities: A Critical Review. Biophysical Journal. 1997, pp 1047-1069.

[137] Bodnarchuk, M. S.; Viner, R.; Michel, J.; Essex, J. W. Strategies to Calculate Water Binding Free Energies in Protein-Ligand Complexes. J. Chem. Inf. Model. 2014, 54 (6), 1623-1633.

[138] Trott, O.; Olson, A. J. Software News and Update AutoDock Vina: Improving the Speed and Accuracy of Docking with a New Scoring Function, Efficient Optimization, and Multithreading. J. Comput. Chem. 2010, 31 (2), 455-461.

[139] Ross, G. A.; Morris, G. M.; Biggin, P. C. Rapid and Accurate Prediction and Scoring of Water Molecules in Protein Binding Sites. PLoS One 2012, 7 (3), e32036.

[140] Hartshorn, M. J.; Verdonk, M. L.; Chessari, G.; Brewerton, S. C.; Mooij, W. T. M.; Mortenson, P. N.; Murray, C. W. Diverse, High-Quality Test Set for the Validation of Protein-Ligand Docking Performance. J. Med. Chem. 2007, 50 (4), 726-741.

[141] Randjelovic, J.; Eric, S.; Savic, V. In Silico Design of Small Molecule Inhibitors of CDK9/cyclin T1 Interaction. J. Mol. Graph. Model. 2014, 50, $100-112$.

[142] Zapata-Torres, G.; Fierro, A.; Barriga-González, G.; Salgado, J. C.; CelisBarros, C. Revealing Monoamine Oxidase B Catalytic Mechanisms by Means 
This is a post print version of the article published in Curr Med Chem. 2018 May 13. doi: $10.2174 / 0929867325666180514110824$

http://www.eurekaselect.com/162094/article

of the Quantum Chemical Cluster Approach. J. Chem. Inf. Model. 2015, 55 (7), 1349-1360.

[143] Fierro, A.; Edmondson, D. E.; Celis-Barros, C.; Rebolledo-Fuentes, M.; Zapata-Torres, G. Why P-OMe- and P-Cl- $\beta$-Methylphenethylamines Display Distinct Activities upon MAO-B Binding. PLoS One 2016, 11 (5), e0154989.

[144] Bartl, J.; Palazzesi, F.; Parrinello, M.; Hommers, L.; Riederer, P.; Walitza, S.; Grünblatt, E. The Impact of Methylphenidate and Its Enantiomers on Dopamine Synthesis and Metabolism in Vitro. Prog. NeuroPsychopharmacology Biol. Psychiatry 2017, 79, 281-288.

[145] Morozenko, A.; Stuchebrukhov, A. A. Dowser++, a New Method of Hydrating Protein Structures. Proteins Struct. Funct. Bioinforma. 2016, 84 (10), 13471357.

[146] Zhang, L.; Hermans, J. Hydrophilicity of Cavities in Proteins. Proteins Struct. Funct. Genet. 1996, 24 (4), 433-438.

[147] Sridhar, A.; Ross, G. A.; Biggin, P. C. Waterdock 2.0: Water Placement Prediction for Holo-Structures with a Pymol Plugin. PLoS One 2017, 12 (2), $\mathrm{e} 0172743$.

[148] OpenEye. SZMAP 1.2.1.4. OpenEye Scientific Software: Santa Fe, NM 2015.

[149] Goodford, P. J. A Computational Procedure for Determining Energetically Favorable Binding Sites on Biologically Important Macromolecules. J. Med. Chem. 1985, 28 (7), 849-857.

[150] Grant, J. A.; Pickup, B. T.; Nicholls, A. A Smooth Permittivity Function for Poisson-Boltzmann Solvation Methods. J. Comput. Chem. 2001, 22 (6), 608640.

[151] Bayden, A. S.; Moustakas, D. T.; Joseph-McCarthy, D.; Lamb, M. L. Evaluating Free Energies of Binding and Conservation of Crystallographic Waters Using SZMAP. J. Chem. Inf. Model. 2015, 55 (8), 1552-1565.

[152] Verdonk, M. L.; Cole, J. C.; Taylor, R. SuperStar: A Knowledge-Based Approach for Identifying Interaction Sites in Proteins. J. Mol. Biol. 1999, 289 (4), 1093-1108.

[153] Verdonk, M. L.; Cole, J. C.; Watson, P.; Gillet, V.; Willett, P. SuperStar: Improved Knowledge-Based Interaction Fields for Protein Binding Sites. $J$. Mol. Biol. 2001, 307 (3), 841-859.

[154] Boer, D. R.; Kroon, J.; Cole, J. C.; Smith, B.; Verdonk, M. L. SuperStar: Comparison of CSD and PDB-Based Interaction Fields as a Basis for the Prediction of Protein-Ligand Interactions. J. Mol. Biol. 2001, 312 (1), 275-287.

[155] Bruno, I. J.; Cole, J. C.; Lommerse, J. P. M.; Rowland, R. S.; Taylor, R.; Verdonk, M. L. IsoStar: A Library of Information about Nonbonded Interactions. J. Comput. Aided. Mol. Des. 1997, 11 (6), 525-537.

[156] Kraemer, O.; Hazemann, I.; Podjarny, A. D.; Klebe, G. Virtual Screening for Inhibitors of Human Aldose Reductase. Proteins Struct. Funct. Bioinforma. 2004, 55 (4), 814-823. 
This is a post print version of the article published in Curr Med Chem. 2018 May 13. doi: $10.2174 / 0929867325666180514110824$

http://www.eurekaselect.com/162094/article

[157] Nissink, J. W. M.; Taylor, R. Combined Use of Physicochemical Data and Small-Molecule Crystallographic Contact Propensities to Predict Interactions in Protein Binding Sites. Org. Biomol. Chem. 2004, 2 (22), 3238-3249.

[158] Matter, H.; Will, D. W.; Nazaré, M.; Schreuder, H.; Laux, V.; Wehner, V. Structural Requirements for Factor Xa Inhibition by 3-Oxybenzamides with Neutral P1 Substituents: Combining X-Ray Crystallography, 3D-QSAR, and Tailored Scoring Functions. J. Med. Chem. 2005, 48 (9), 3290-3312.

[159] Serrano, D. R.; Mugheirbi, N. A.; O’Connell, P.; Leddy, N.; Healy, A. M.; Tajber, L. Impact of Substrate Properties on the Formation of Spherulitic Films: A Case Study of Salbutamol Sulfate. Cryst. Growth Des. 2016, 16 (7), 3853-3858.

[160] Saito, R.; Hoshi, M.; Kato, A.; Ishikawa, C.; Komatsu, T. Green Fluorescent Protein Chromophore Derivatives as a New Class of Aldose Reductase Inhibitors. Eur. J. Med. Chem. 2017, 125, 965-974.

[161] Söderholm, A. A.; Lehtovuori, P. T.; Nyrönen, T. H. Three-Dimensional Structure-Activity Relationships of Nonsteroidal Ligands in Complex with Androgen Receptor Ligand-Binding Domain. J. Med. Chem. 2005, 48 (4), 917925.

[162] Rossato, G.; Ernst, B.; Vedani, A.; Smie??ko, M. AcquaAlta: A Directional Approach to the Solvation of Ligand-Protein Complexes. J. Chem. Inf. Model. 2011, 51 (8), 1867-1881.

[163] Dunitz, J. D. The Entropic Cost of Bound Water in Crystals and Biomolecules. Science (80-. ) 1994, 264 (5159), 670-670.

[164] Friesner, R. A.; Murphy, R. B.; Repasky, M. P.; Frye, L. L.; Greenwood, J. R.; Halgren, T. A.; Sanschagrin, P. C.; Mainz, D. T. Extra Precision Glide: Docking and Scoring Incorporating a Model of Hydrophobic Enclosure for Protein-Ligand Complexes. J. Med. Chem. 2006, 49 (21), 6177-6196.

[165] Jones, G.; Willett, P.; Glen, R. C. Molecular Recognition of Receptor Sites Using a Genetic Algorithm with a Description of Desolvation. J. Mol. Biol. 1995, 245 (1), 43-53.

[166] Verdonk, M. L.; Chessari, G.; Cole, J. C.; Hartshorn, M. J.; Murray, C. W.; Nissink, J. W. M.; Taylor, R. D.; Taylor, R. Modeling Water Molecules in Protein-Ligand Docking Using GOLD. J. Med. Chem. 2005, 48 (20), 65046515.

[167] Ntie-Kang, F.; Nwodo, J. N.; Ibezim, A.; Simoben, C. V.; Karaman, B.; Ngwa, V. F.; Sippl, W.; Adikwu, M. U.; Mbaze, L. M. a. Molecular Modeling of Potential Anticancer Agents from African Medicinal Plants. J. Chem. Inf. Model. 2014, 54 (9), 2433-2450.

[168] Pisani, L.; Barletta, M.; Soto-Otero, R.; Nicolotti, O.; Mendez-Alvarez, E.; Catto, M.; Introcaso, A.; Stefanachi, A.; Cellamare, S.; Altomare, C.; Carotti, A. Discovery, Biological Evaluation, and Structure-Activity and -Selectivity Relationships of 6'-Substituted ( E )-2-(Benzofuran-3(2 H )-Ylidene)- N Methylacetamides, a Novel Class of Potent and Selective Monoamine Oxidase 
This is a post print version of the article published in Curr Med Chem. 2018 May 13. doi: $10.2174 / 0929867325666180514110824$

http://www.eurekaselect.com/162094/article

Inhibitors. J. Med. Chem. 2013, 56 (6), 2651-2664.

[169] Berg, L.; Andersson, C. D.; Artursson, E.; Hörnberg, A.; Tunemalm, A.-K.; Linusson, A.; Ekström, F. Targeting Acetylcholinesterase: Identification of Chemical Leads by High Throughput Screening, Structure Determination and Molecular Modeling. PLoS One 2011, 6 (11), e26039.

[170] Mouchlis, V. D.; Magrioti, V.; Barbayianni, E.; Cermak, N.; Oslund, R. C.; Mavromoustakos, T. M.; Gelb, M. H.; Kokotos, G. Inhibition of Secreted Phospholipases A2 by 2-Oxoamides Based on $\alpha$-Amino Acids: Synthesis, in Vitro Evaluation and Molecular Docking Calculations. Bioorganic Med. Chem. 2011, 19 (2), 735-743.

[171] Santos, R.; Hritz, J.; Oostenbrink, C. Role of Water in Molecular Docking Simulations of Cytochrome P450 2D6. J. Chem. Inf. Model. 2010, 50 (1), 146154.

[172] Murray, C. W.; Carr, M. G.; Callaghan, O.; Chessari, G.; Congreve, M.; Cowan, S.; Coyle, J. E.; Downham, R.; Figueroa, E.; Frederickson, M.; Graham, B.; McMenamin, R.; O’Brien, M. A.; Patel, S.; Phillips, T. R.; Williams, G.; Woodhead, A. J.; Woolford, A. J. A. Fragment-Based Drug Discovery Applied to Hsp90. Discovery of Two Lead Series with High Ligand Efficiency. J. Med. Chem. 2010, 53 (16), 5942-5955.

[173] Vasanthanathan, P.; Hritz, J.; Taboureau, O.; Olsen, L.; Jørgensen, F. S.; Vermeulen, N. P. E.; Oostenbrink, C. Virtual Screening and Prediction of Site of Metabolism for Cytochrome P450 1A2 Ligands. J. Chem. Inf. Model. 2009, 49 (1), 43-52.

[174] Li, Y.; Shen, J.; Sun, X.; Li, W.; Liu, G.; Tang, Y. Accuracy Assessment of Protein-Based Docking Programs against RNA Targets. J. Chem. Inf. Model. 2010, 50 (6), 1134-1146.

[175] Davis, I. W.; Baker, D. RosettaLigand Docking with Full Ligand and Receptor Flexibility. J. Mol. Biol. 2009, 385 (2), 381-392.

[176] Lemmon, G.; Meiler, J. Towards Ligand Docking Including Explicit Interface Water Molecules. PLoS One 2013, 8 (6), e67536.

[177] Meiler, J.; Baker, D. ROSETTALIGAND: Protein-Small Molecule Docking with Full Side-Chain Flexibility. Proteins Struct. Funct. Genet. 2006, 65 (3), $538-548$.

[178] Thomsen, R.; Christensen, M. H. MolDock: A New Technique for HighAccuracy Molecular Docking. J. Med. Chem. 2006, 49 (11), 3315-3321.

[179] Huey, R.; Morris, G. M.; Olson, A. J.; Goodsell, D. S. Software News and Update a Semiempirical Free Energy Force Field with Charge-Based Desolvation. J. Comput. Chem. 2007, 28 (6), 1145-1152.

[180] Lie, M. A.; Thomsen, R.; Pedersen, C. N. S.; Schiøtt, B.; Christensen, M. H. Molecular Docking with Ligand Attached Water Molecules. J. Chem. Inf. Model. 2011, 51 (4), 909-917.

[181] Paulsen, E. S.; Villadsen, J.; Tenori, E.; Liu, H.; Bonde, D. F.; Lie, M. A.; 
This is a post print version of the article published in Curr Med Chem. 2018 May 13. doi: $10.2174 / 0929867325666180514110824$

http://www.eurekaselect.com/162094/article

Bublitz, M.; Olesen, C.; Autzen, H. E.; Dach, I.; Sehgal, P.; Nissen, P.; Møller, J. V.; Schiøtt, B.; Christensen, S. B. Water-Mediated Interactions Influence the Binding of Thapsigargin to Sarco/endoplasmic Reticulum Calcium Adenosinetriphosphatase. J. Med. Chem. 2013, 56 (9), 3609-3619.

[182] Forli, S.; Olson, A. J. A Force Field with Discrete Displaceable Waters and Desolvation Entropy for Hydrated Ligand Docking. J. Med. Chem. 2012, 55 (2), 623-638.

[183] Forli, S.; Huey, R.; Pique, M. E.; Sanner, M. F.; Goodsell, D. S.; Olson, A. J. Computational Protein-Ligand Docking and Virtual Drug Screening with the AutoDock Suite. Nat. Protoc. 2016, 11 (5), 905-919.

[184] Shityakov, S.; Salmas, R. E.; Durdagi, S.; Roewer, N.; Förster, C.; Broscheit, J. Solubility Profiles, Hydration and Desolvation of Curcumin Complexed with $\gamma$ Cyclodextrin and Hydroxypropyl- $\gamma$-Cyclodextrin. J. Mol. Struct. 2017, 1134, 91-98.

[185] Yuan, H.; Wu, J.; Wang, X.; Chen, J.; Zhong, Y.; Huang, Q.; Nan, P. Computational Identification of Amino-Acid Mutations That Further Improve the Activity of a Chalcone-Flavonone Isomerase from Glycine Max. Front. Plant Sci. 2017, 8, 248.

[186] Patel, D.; Antwi, J.; Koneru, P. C.; Serrao, E.; Forli, S.; Kessl, J. J.; Feng, L.; Deng, N.; Levy, R. M.; Fuchs, J. R.; Olson, A. J.; Engelman, A. N.; Bauman, J. D.; Kvaratskhelia, M.; Arnold, E. A New Class of Allosteric HIV-1 Integrase Inhibitors Identified by Crystallographic Fragment Screening of the Catalytic Core Domain. J. Biol. Chem. 2016, 291 (45), 23569-23577.

[187] Taliani, S.; Pugliesi, I.; Barresi, E.; Salerno, S.; Marchand, C.; Agama, K.; Simorini, F.; La Motta, C.; Marini, A. M.; Di Leva, F. S.; Marinelli, L.; Cosconati, S.; Novellino, E.; Pommier, Y.; Di Santo, R.; Da Settimo, F. Phenylpyrazolo[1,5-A]quinazolin-5(4 H)-One: A Suitable Scaffold for the Development of Noncamptothecin Topoisomerase I (Top1) Inhibitors. J. Med. Chem. 2013, 56 (18), 7458-7462.

[188] Tamborini, L.; Pinto, A.; Smith, T. K.; Major, L. L.; Iannuzzi, M. C.; Cosconati, S.; Marinelli, L.; Novellino, E.; Lo Presti, L.; Wong, P. E.; Barrett, M. P.; DeMicheli, C.; Conti, P. Synthesis and Biological Evaluation of CTP Synthetase Inhibitors as Potential Agents for the Treatment of African Trypanosomiasis. ChemMedChem 2012, 7 (9), 1623-1634.

[189] Leach, A. R.; Kuntz, I. D. Conformational Analysis of Flexible Ligands in Macromolecular Receptor Sites. J. Comput. Chem. 1992, 13 (6), 730-748.

[190] Rarey, M.; Kramer, B.; Lengauer, T. The Particle Concept: Placing Discrete Water Molecules during Protein-Ligand Docking Predictions. Proteins Struct. Funct. Genet. 1999, 34 (1), 17-28.

[191] Duda, R. O.; Hart, P. E. Pattern Classification and Scene Analysis; Wiley: New York, 1973.

[192] Alonso, H.; Bliznyuk, A. A.; Gready, J. E. Combining Docking and Molecular Dynamic Simulations in Drug Design. Med. Res. Rev. 2006, 26 (5), 531-568. 
This is a post print version of the article published in Curr Med Chem. 2018 May 13. doi: $10.2174 / 0929867325666180514110824$

http://www.eurekaselect.com/162094/article

[193] Durrant, J. D.; McCammon, J. A. Molecular Dynamics Simulations and Drug Discovery. BMC Biol. 2011, 9 (1), 71.

[194] Kerrigan, J. E. Molecular Dynamics Simulations in Drug Design. In In Silico Models for Drug Discovery; Humana Press, Totowa, NJ, 2013; Vol. 993, pp 95-113.

[195] Zhang, J.-L.; Zheng, Q.-C.; Chu, W.-T.; Zhang, H.-X. Drug Design Benefits from Molecular Dynamics: Some Examples. Curr. Comput. Aided. Drug Des. 2013, 9 (4), 532-546.

[196] Zhao, H.; Caflisch, A. Molecular Dynamics in Drug Design. Eur. J. Med. Chem. 2014, 91, 4-14.

[197] Borhani, D. W.; Shaw, D. E. The Future of Molecular Dynamics Simulations in Drug Discovery. J. Comput. Aided. Mol. Des. 2012, 26 (1), 15-26.

[198] Hamelberg, D.; McCammon, J. A. Standard Free Energy of Releasing a Localized Water Molecule from the Binding Pockets of Proteins: DoubleDecoupling Method. J. Am. Chem. Soc. 2004, 126 (24), 7683-7689.

[199] Price, D. J.; Jorgensen, W. L. Improved Convergence of Binding Affinities with Free Energy Perturbation: Application to Nonpeptide Ligands with pp60srcSH2 Domain. J. Comput. Aided. Mol. Des. 2001, 15 (8), 681-695.

[200] Helms, V.; Wade, R. C. Computational Alchemy to Calculate Absolute Protein-Ligand Binding Free Energy. J. Am. Chem. Soc. 1998, 120 (12), 2710 2713.

[201] Williams-Noonan, B. J.; Yuriev, E.; Chalmers, D. K. Free Energy Methods in Drug Design: The Prospects of "Alchemical Perturbation" in Medicinal Chemistry. J. Med. Chem. 2017, 61 (3), 638-649.

[202] Abel, R.; Mondal, S.; Masse, C.; Greenwood, J.; Harriman, G.; Ashwell, M. A.; Bhat, S.; Wester, R.; Frye, L.; Kapeller, R.; Friesner, R. A. Accelerating Drug Discovery through Tight Integration of Expert Molecular Design and Predictive Scoring. Curr. Opin. Struct. Biol. 2017, 43, 38-44.

[203] Abel, R.; Wang, L.; Harder, E. D.; Berne, B. J.; Friesner, R. A. Advancing Drug Discovery through Enhanced Free Energy Calculations. Acc. Chem. Res. 2017, 50 (7), 1625-1632.

[204] Ciordia, M.; Pérez-Benito, L.; Delgado, F.; Trabanco, A. A.; Tresadern, G. Application of Free Energy Perturbation for the Design of BACE1 Inhibitors. J. Chem. Inf. Model. 2016, 56 (9), 1856-1871.

[205] Lenselink, E. B.; Louvel, J.; Forti, A. F.; Van Veldhoven, J. P. D.; De Vries, H.; Mulder-Krieger, T.; McRobb, F. M.; Negri, A.; Goose, J.; Abel, R.; Van Vlijmen, H. W. T.; Wang, L.; Harder, E.; Sherman, W.; Ijzerman, A. P.; Beuming, T. Predicting Binding Affinities for GPCR Ligands Using FreeEnergy Perturbation. ACS Omega 2016, 1 (2), 293-304.

[206] Lovering, F.; Aevazelis, C.; Chang, J.; Dehnhardt, C.; Fitz, L.; Han, S.; Janz, K.; Lee, J.; Kaila, N.; McDonald, J.; Moore, W.; Moretto, A.; Papaioannou, N.; Richard, D.; Ryan, M. S.; Wan, Z. K.; Thorarensen, A. Imidazotriazines: 
This is a post print version of the article published in Curr Med Chem. 2018 May 13. doi: $10.2174 / 0929867325666180514110824$

http://www.eurekaselect.com/162094/article

Spleen Tyrosine Kinase (Syk) Inhibitors Identified by Free-Energy

Perturbation (FEP). ChemMedChem 2016, 11 (2), 217-233.

[207] Massova, I.; Kollman, P. A. Combined Molecular Mechanical and Continuum Solvent Approach (MM-PBSA/GBSA) to Predict Ligand Binding. Perspect. Drug Discov. Des. 2000, 18 (1), 113-135.

[208] Kollman, P. A.; Massova, I.; Reyes, C.; Kuhn, B.; Huo, S.; Chong, L.; Lee, M.; Lee, T.; Duan, Y.; Wang, W.; Donini, O.; Cieplak, P.; Srinivasan, J.; Case, D. A.; Cheatham, T. E. Calculating Structures and Free Energies of Complex Molecules: Combining Molecular Mechanics and Continuum Models. Acc. Chem. Res. 2000, 33 (12), 889-897.

[209] Kuhn, B.; Kollman, P. A. Binding of a Diverse Set of Ligands to Avidin and Streptavidin: An Accurate Quantitative Prediction of Their Relative Affinities by a Combination of Molecular Mechanics and Continuum Solvent Models. J. Med. Chem. 2000, 43 (20), 3786-3791.

[210] Srinivasan, J.; Cheatham, T. E.; Cieplak, P.; Kollman, P. A.; Case, D. A. Continuum Solvent Studies of the Stability of DNA, RNA, and Phosphoramidate - DNA Helices. J. Am. Chem. Soc. 1998, 120 (37), 94019409.

[211] Sun, H.; Li, Y.; Tian, S.; Xu, L.; Hou, T. Assessing the Performance of MM/PBSA and MM/GBSA Methods. 4. Accuracies of MM/PBSA and MM/GBSA Methodologies Evaluated by Various Simulation Protocols Using PDBbind Data Set. Phys. Chem. Chem. Phys. 2014, 16 (31), 16719-16729.

[212] Sun, H.; Li, Y.; Shen, M.; Tian, S.; Xu, L.; Pan, P.; Guan, Y.; Hou, T. Assessing the Performance of MM/PBSA and MM/GBSA Methods. 5. Improved Docking Performance Using High Solute Dielectric Constant MM/GBSA and MM/PBSA Rescoring. Phys. Chem. Chem. Phys. 2014, 16 (40), 22035-22045.

[213] Xu, L.; Sun, H.; Li, Y.; Wang, J.; Hou, T. Assessing the Performance of MM/PBSA and MM/GBSA Methods. 3. The Impact of Force Fields and Ligand Charge Models. J. Phys. Chem. B 2013, 117 (28), 8408-8421.

[214] Chen, F.; Liu, H.; Sun, H.; Pan, P.; Li, Y.; Li, D.; Hou, T. Assessing the Performance of the MM/PBSA and MM/GBSA Methods. 6. Capability to Predict Protein-protein Binding Free Energies and Re-Rank Binding Poses Generated by Protein-protein Docking. Phys. Chem. Chem. Phys. 2016, 18 (32), 22129-22139.

[215] Simonson, T. Binding Free Energies and Free Energy Differences. Curr. Opin. Struct. Biol. 2001, 11, 243-252.

[216] Maffucci, I.; Contini, A. Tuning the Solvation Term in the MM-PBSA/GBSA Binding Affinity Predictions. In Frontiers in Computational Chemistry; UlHaq, Z., Madura, J. D., Eds.; Bentham Science Publishers, 2015; Vol. 1, pp 82120.

[217] Maffucci, I.; Contini, A. Explicit Ligand Hydration Shells Improve the Correlation between MM-PB/GBSA Binding Energies and Experimental 
This is a post print version of the article published in Curr Med Chem. 2018 May 13. doi: $10.2174 / 0929867325666180514110824$

http://www.eurekaselect.com/162094/article

Activities. J. Chem. Theory Comput. 2013, 9 (6), 2706-2717.

[218] Maffucci, I.; Contini, A. Improved Computation of Protein-Protein Relative Binding Energies with the Nwat-MMGBSA Method. J. Chem. Inf. Model. 2016, 56 (9), 1692-1704.

[219] Treesuwan, W.; Hannongbua, S. Bridge Water Mediates Nevirapine Binding to Wild Type and Y181C HIV-1 Reverse Transcriptase-Evidence from Molecular Dynamics Simulations and MM-PBSA Calculations. J. Mol. Graph. Model. 2009, 27 (8), 921-929.

[220] Wong, S.; Amaro, R. E.; Andrew McCammon, J. MM-PBSA Captures Key Role of Intercalating Water Molecules at a Protein-Protein Interface. J. Chem. Theory Comput. 2009, 5 (2), 422-429.

[221] Nurisso, A.; Blanchard, B.; Audfray, A.; Rydner, L.; Oscarson, S.; Varrot, A.; Imberty, A. Role of Water Molecules in Structure and Energetics of Pseudomonas Aeruginosa Lectin I Interacting with Disaccharides. J. Biol. Chem. 2010, 285 (26), 20316-20327.

[222] Liu, J.; He, X.; Zhang, J. Z. H. Improving the Scoring of Protein-Ligand Binding Affinity by Including the Effects of Structural Water and Electronic Polarization. J. Chem. Inf. Model. 2013, 53 (6), 1306-1314.

[223] Checa, A.; Ortiz, A. R.; De Pascual-Teresa, B.; Gago, F. Assessment of Solvation Effects on Calculated Binding Affinity Differences: Trypsin Inhibition by Flavonoids as a Model System for Congeneric Series. J. Med. Chem. 1997, 40 (25), 4136-4145.

[224] Greenidge, P. A.; Kramer, C.; Mozziconacci, J. C.; Wolf, R. M. MM/GBSA Binding Energy Prediction on the PDBbind Data Set: Successes, Failures, and Directions for Further Improvement. J. Chem. Inf. Model. 2013, 53 (1), 201209.

[225] Wallnoefer, H. G.; Liedl, K. R.; Fox, T. A Challenging System: Free Energy Prediction for Factor Xa. J. Comput. Chem. 2011, 32 (8), 1743-1752.

[226] Henchman, R. H.; McCammon, J. A. Structural and Dynamic Properties of Water around Acetylcholinesterase. Protein Sci. 2009, 11 (9), 2080-2090.

[227] Schiffer, C.; Hermans, J. Promise of Advances in Simulation Methods for Protein Crystallography: Implicit Solvent Models, Time-Averaging Refinement, and Quantum Mechanical Modeling. Methods Enzymol. 2003, $374,412-461$.

[228] Staker, B. L.; Hjerrild, K.; Feese, M. D.; Behnke, C. A.; Burgin, A. B.; Stewart, L. The Mechanism of Topoisomerase I Poisoning by a Camptothecin Analog. Proc. Natl. Acad. Sci. U. S. A. 2002, 99 (24), 15387-15392.

[229] Aldeghi, M.; Bodkin, M. J.; Knapp, S.; Biggin, P. C. Statistical Analysis on the Performance of Molecular Mechanics Poisson-Boltzmann Surface Area versus Absolute Binding Free Energy Calculations: Bromodomains as a Case Study. J. Chem. Inf. Model. 2017, 57 (9), 2203-2221.

[230] Kannan, S.; Pradhan, M. R.; Cherian, J.; Joseph, T. L.; Poh, Z. Y.; Hai Yan, Y.; 
This is a post print version of the article published in Curr Med Chem. 2018 May 13. doi: $10.2174 / 0929867325666180514110824$

http://www.eurekaselect.com/162094/article

Melvyn, H.; Boping, L.; Jeffrey, H.; Nacro, K.; Verma, C. S. Small Molecules Targeting the Inactive Form of the Mnk1/2 Kinases. ACS Omega 2017, 2 (11), 7881-7891.

[231] Maffucci, I.; Hu, X.; Fumagalli, V.; Contini, A. An Efficient Implementation of the Nwat-MMGBSA Method to Rescore Docking Results in MediumThroughput Virtual Screenings. Front. Chem. 2018, doi: 10.3389/fchem.2018.00043.

[232] Hou, T.; Wang, J.; Li, Y.; Wang, W. Assessing the Performance of the Molecular mechanics/Poisson Boltzmann Surface Area and Molecular Mechanics/generalized Born Surface Area Methods. II. The Accuracy of Ranking Poses Generated from Docking. J. Comput. Chem. 2011, 32 (5), 866877.

[233] Hou, T.; Wang, J.; Li, Y.; Wang, W. Assessing the Performance of the MM/PBSA and MM/GBSA Methods. 1. The Accuracy of Binding Free Energy Calculations Based on Molecular Dynamics Simulations. J. Chem. Inf. Model. 2011, 51 (1), 69-82.

[234] Weis, A.; Katebzadeh, K.; Söderhjelm, P.; Nilsson, I.; Ryde, U. Ligand Affinities Predicted with the MM/PBSA Method: Dependence on the Simulation Method and the Force Field. J. Med. Chem. 2006, 49 (22), 65966606.

[235] Case, D. A. Normal Mode Analysis of Protein Dynamics. Curr. Opin. Struct. Biol. 1994, 4 (2), 285-290.

[236] Duan, L.; Liu, X.; Zhang, J. Z. H. Interaction Entropy: A New Paradigm for Highly Efficient and Reliable Computation of Protein-Ligand Binding Free Energy. J. Am. Chem. Soc. 2016, 138 (17), 5722-5728.

[237] Mikulskis, P.; Genheden, S.; Ryde, U. Effect of Explicit Water Molecules on Ligand-Binding Affinities Calculated with the MM/GBSA Approach. J. Mol. Model. 2014, 20 (6), 2273.

[238] Maffucci, I.; Hu, X.; Fumagalli, V.; Contini, A. An Efficient Implementation of the Nwat-MMGBSA Method to Rescore Docking Results in MediumThroughput Virtual Screenings https://doi.org/10.26434/chemrxiv.5387575.v1. 